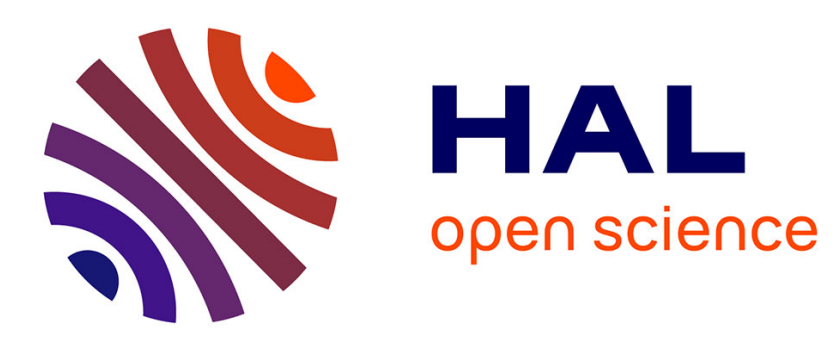

\title{
Anisotropic unilateral damage with initial orthotropy: A micromechanics-based approach
}

\author{
Cristina Goidescu, Hélène Welemane, Olivier Pantalé, Moussa Karama, \\ Djimédo Kondo
}

\section{- To cite this version:}

Cristina Goidescu, Hélène Welemane, Olivier Pantalé, Moussa Karama, Djimédo Kondo. Anisotropic unilateral damage with initial orthotropy: A micromechanics-based approach. International Journal of Damage Mechanics, 2015, vol. 24 ( $\mathrm{n}^{\circ}$ 3), pp. 313-337. 10.1177/1056789514532299 . hal-01174240

\author{
HAL Id: hal-01174240 \\ https://hal.science/hal-01174240
}

Submitted on 8 Jul 2015

HAL is a multi-disciplinary open access archive for the deposit and dissemination of scientific research documents, whether they are published or not. The documents may come from teaching and research institutions in France or abroad, or from public or private research centers.
L'archive ouverte pluridisciplinaire HAL, est destinée au dépôt et à la diffusion de documents scientifiques de niveau recherche, publiés ou non, émanant des établissements d'enseignement et de recherche français ou étrangers, des laboratoires publics ou privés. 


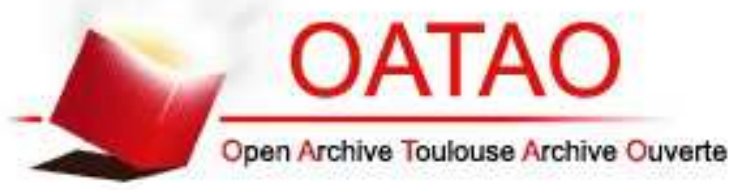

\section{Open Archive Toulouse Archive Ouverte (OATAO)}

OATAO is an open access repository that collects the work of Toulouse researchers and makes it freely available over the web where possible.

This is an author-deposited version published in: http://oatao.univ-toulouse.fr/ Eprints ID: 13924

To link to this article: DOI:10.1177/1056789514532299

http://dx.doi.org/10.1177/1056789514532299

\section{To cite this version:}

Goidescu, Cristina and Welemane, Hélène and Pantalé, Olivier and Karama, Moussa and Kondo, Djimédo Anisotropic unilateral damage with initial orthotropy: A micromechanics-based approach. (2015) International Journal of Damage Mechanics, vol. 24 ( $\left.\mathrm{n}^{\circ} 3\right)$. pp. 313-337. ISSN 1056-7895

Any correspondence concerning this service should be sent to the repository administrator: staff-oatao@ listes-diff.inp-toulouse.fr 


\title{
Anisotropic unilateral damage with initial orthotropy: A micromechanics-based approach
}

\author{
C Goidescu', H Welemane', O Pantalé', M Karama' and \\ D Kondo ${ }^{2}$
}

\begin{abstract}
A micromechanics-based damage model able to describe the brittle response of initially anisotropic materials is presented. A special emphasis is put on the account of damage-induced anisotropy and unilateral behaviour related to microcracks closure effects. These both features clearly influence the inelastic deformation of microcracked materials and lead to even more complex consequences in the context of initial anisotropy. The aim of this work is then to derive a new strain-based formulation which allows representing the related interactions between all these phenomena. This is achieved through a recent two-dimensional energy-based micromechanical analysis that accounts for the fully anisotropic multilinear response of orthotropic materials weakened by arbitrarily oriented microcracks. On the other hand, the thermodynamics framework gives a standard procedure for the development of the damage evolution law. Throughout the paper, attention is put on the mathematical and thermodynamical consistency of the model to avoid difficulties usually associated to the simultaneous description of damageinduced anisotropy and unilateral effects. In addition to elastic constants, the model requires the identification of only two parameters related to damage evolution. The model has been implemented within the commercial finite-element code ABAQUS, and various numerical simulations are presented to illustrate its capabilities. Especially, evolution of the material symmetry and influence of opening-closure states of microcracks on the damage process are illustrated in the case of brittle matrix composites subjected to different loading cases (axis and off-axis loads, tension and compression, tension followed by compression).
\end{abstract}

\section{Keywords}

Damage model, microcracking, anisotropy, micromechanics, unilateral effects

\footnotetext{
'Laboratoire Génie de Production, INP/ENIT, Université de Toulouse, Tarbes, France

${ }^{2}$ Institut Jean le Rond d'Alembert, Université de Paris VI, Paris, France

Corresponding author:

H Welemane, Ecole Nationale d'Ingénieurs de Tarbes, 47 Avenue d'Azereix, F-65016 Tarbes cedex, France.

Email: Helene.Welemane@enit.fr
} 


\section{Introduction}

The inelastic stress-strain response of brittle materials is governed by the existence and growth of diffuse microcracking. At the macroscopic scale, this deterioration process leads to various complex phenomena clearly identified during experimental tests such as elastic properties degradation, loadinduced anisotropy or microcracks opening-closure effects (Allix et al., 1993; Baste and Aristégui, 1998; Goidescu et al. 2013a; Homand et al., 2000; Morvan and Baste, 1998; Reinhardt, 1984). Constitutive models able to describe such irreversible behaviour are generally formulated by means of continuum damage mechanics (CDM; Krajcinovic, 1996; Murakami, 2012). Through the definition of internal variables and irreversible thermodynamics framework, CDM provides efficient macroscopic modelling tools for engineering analysis. Especially, strain-based formulation offers the most suitable framework for finite-element implementation and numerical developments.

For initially isotropic materials (concrete, ceramics, some rocks, etc.), several CDM attempts have been done to represent simultaneously the anisotropic damage due to oriented defects and the unilateral behaviour related to microcracks opening-closure. Yet, two major difficulties arise in this case: first, the mathematical and thermodynamical consistency of the formulations (Carol and Willam, 1996; Chaboche, 1992; Cormery and Welemane, 2002) and then their physical background (Chaboche, 1999; Welemane and Cormery, 2002). Regarding this last point, some authors suggest to introduce micromechanical arguments to ensure a better physical justification to modelling choices (Dragon and Halm, 2004; Krajcinovic, 1987, 2000). Especially, recovery effects related to microcracks closure generally suffer of a lack of experimental characterization. Micromechanics provide then an efficient alternative (let mention for instance strain-based models of Andrieux et al., 1986 in 2D context; Ju, 1990; Pensée et al., 2002; Welemane and Goidescu, 2010 in 3D case).

The description of all these damage features is even more complex for initially anisotropic materials such as fiber-reinforced composites or sedimentary rocks. It is worth noting that addressing the interaction between primary anisotropy and damage-induced one is itself a difficult task (see for instance Cazacu et al., 2007; Feltman and Santare, 1999; Monchiet et al., 2012; Thionnet and Martin, 2006; Wang et al., 2009). The additional representation of damage activation-deactivation effects is then most often restricted to damage in some specific directions: either the material principal axes (Chaboche et al., 1995; Thionnet and Renard, 1999), or the principal directions of a tensorial quantity such as damage variable or compliance tensor (Desmorat, 2000; Halm et al., 2002; Ladevéze, 1993; Maire and Lesne, 1998). Moreover, existing formulations generally exhibit same above-mentioned inconsistencies, in particular the physical motivation of deactivation representation. Only few publications tried to improve them through some micromechanical analyses (see works on composite materials of Allen et al., 1987; Chaboche and Maire, 2002; Talreja, 1985, 1991; Thionnet and Renard, 1999).

Recently, the homogenization-based approach initially proposed by Andrieux et al. (1986) for isotropic media has been extended to the anisotropic context (Goidescu et al., 2013b). Under the assumptions of non-interacting frictionless microcracks in dilute concentration, such procedure has led to the closed-form expression of the macroscopic free energy corresponding to two-dimensional (2D) initially orthotropic media weakened by open or closed microcracks with arbitrary orientation. Results provide then a clear quantification of interactions between primary and damage-induced anisotropies and activation-deactivation effects for a fixed density of microcracks. Combined effects of these phenomena have been clearly illustrated on the elastic properties of ceramic composites.

Such study provides the fundamental basis of the anisotropic unilateral damage model for initially orthotropic materials proposed in this paper. Our original CDM approach is indeed based on the free energy derived by this micromechanical procedure and evolving damage is described by 
means of standard arguments. Basically, the model constitutes an extension to the case of initially orthotropic materials of a previous approach proposed by Andrieux et al. (1986). One of the main contributions of this micromechanically based model is to account for the complex growth of distributed damage with the combined influence of initial anisotropy and unilateral effects. Indeed, microcracks orientations are driven both by the load direction and type (tension or compression leading to open or close defects) and also by initial anisotropy but not restricted to the structural axes. Moreover, special attention has been paid to the rigorous formulation of the constitutive law with respect to continuity conditions and thermodynamic principles. It must be emphasized that such a general energy-based formulation developed within a proper and micromechanically justified framework has not been proposed before. It constitutes also an interesting first step to address more complex situations including interactions between defects or dissipative sliding-based behaviour.

The paper is organized as follows. First, we provide the general background and results of the micromechanical analysis exposed by Goidescu et al. (2013b). Then, the following section is dedicated to the complete formulation of the anisotropic damage model, including especially the damage evolution law; some information regarding the numerical integration scheme are also exposed. We finally analyse and discuss in the last part the interaction between primary and microcracks-induced anisotropies on the axis and off-axis responses of composites under tensile and compressive loads. These numerical applications will demonstrate the modelling capabilities of this new constitutive law.

\section{Micromechanics of a 2D microcracked orthotropic medium}

In this part, we recall the main assumptions and results of the homogenization study detailed in Goidescu et al. (2013b). This 2D analysis is based on the approach proposed by Andrieux et al. (1986) and leads to closed-form expressions of the macroscopic free energy of a 2D orthotropic elastic medium weakened by arbitrarily oriented microcracks. The later are assumed open or frictionless closed, non-interacting and in dilute concentration. Small perturbations assumption, rate independent and isothermal conditions are considered in the whole study.

\section{Representative elementary volume}

Consider a representative elementary volume (REV) occupying a cell area $\mathcal{A}$ and having a boundary denoted $\partial \mathcal{A}$ (Figure 1). This REV is made up of an orthotropic linear elastic matrix with symmetry

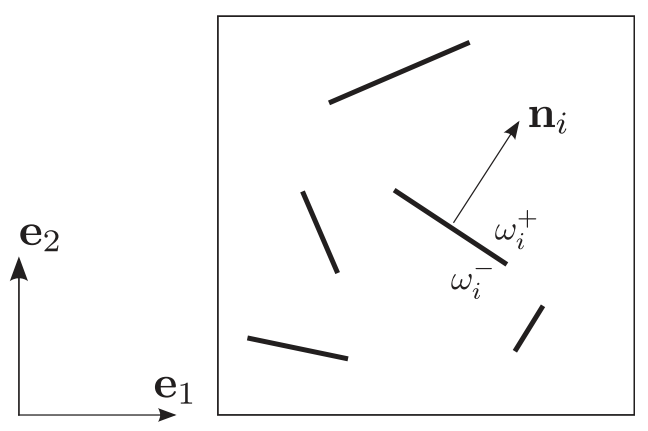

Figure I. Representative elementary volume in the 2D case. 
axes corresponding to the orthonormal basis $\left(\mathbf{e}_{1}, \mathbf{e}_{2}\right)$. The stiffness tensor of the virgin matrix is denoted $\mathbb{C}^{0}$ and reads

$$
\mathbb{C}^{0}=a_{1} \mathbf{I} \otimes \mathbf{I}+a_{2} \underline{\mathbf{I}} \underline{\overline{\mathbf{I}}}+a_{3} \mathbf{A} \otimes \mathbf{A}+a_{4}(\mathbf{A} \otimes \mathbf{I}+\mathbf{I} \otimes \mathbf{A})
$$

Tensor products of two second-order tensors $\mathbf{a}=\left(a_{i j}\right)$ and $\mathbf{b}=\left(b_{i j}\right)$ are defined by

$$
[\mathbf{a} \otimes \mathbf{b}]_{i j k l}=a_{i j} b_{k l} \quad[\mathbf{a} \underline{\bar{\otimes}} \mathbf{b}]_{i j k l}=\frac{1}{2}\left(a_{i k} b_{j l}+a_{i l} b_{j k}\right)
$$

where $\mathbf{I}$ denotes the second-order unit tensor, structural fabric tensor $\mathbf{A}=\mathbf{e}_{1} \otimes \mathbf{e}_{1}$ characterizes the initial orthotropy and parameters $\left\{a_{i}\right\}_{i=1,4}$ are constant coefficients that can be related to engineering moduli in the orthotropic axes

$$
\begin{aligned}
& a_{1}=\frac{E_{2}}{1-v_{12} v_{21}}-2 G_{12}, a_{2}=2 G_{12}, \\
& a_{3}=\frac{\left(1-2 v_{21}\right) E_{1}+E_{2}}{1-v_{12} v_{21}}-4 G_{12}, a_{4}=\frac{E_{2}\left(v_{12}-1\right)}{1-v_{12} v_{21}}+2 G_{12}
\end{aligned}
$$

with Young moduli $E_{1}$ and $E_{2}$ related, respectively, to $\mathbf{e}_{1}$ and $\mathbf{e}_{2}$, Poisson ratios $v_{12}$ and $v_{21}$, and shear modulus $G_{12}$ in the $\left(\mathbf{e}_{1}, \mathbf{e}_{2}\right)$ plane.

This matrix is weakened by an array of $N$ families of flat microcracks with arbitrary orientation relative to orthotropic axes. Microcracks of the $i$ th family are characterized by their unit normal vector $\mathbf{n}_{i}$, mean length $2 l_{i}$ and number $\mathcal{N}_{i}$ per unit surface; $\omega_{i}^{+}$(respectively, $\omega_{i}^{-}$) designates their upper face (respectively, the lower face) and $\omega_{i}=\omega_{i}^{+} \cup ; \omega_{i}^{-}$corresponds to the domain occupied by these cracks. We denote by $\llbracket \mathbf{u}(\mathbf{x}) \rrbracket_{i}=\mathbf{u}\left(\mathbf{x} \in \omega_{i}^{+}\right)-\mathbf{u}\left(\mathbf{x} \in \omega_{i}^{-}\right)$the displacement jump between the two faces $\omega_{i}^{+}$and $\omega_{i}^{-}$for any point $\mathbf{x} \in \omega_{i}$. Classical unilateral conditions are taken into account

$$
\left\{\begin{aligned}
\llbracket u_{n}(\mathbf{x}) \rrbracket_{i}=\llbracket \mathbf{u}(\mathbf{x}) \rrbracket_{i} \cdot \mathbf{n}_{i} & \geq 0 \\
\mathbf{n}_{i} \cdot \boldsymbol{\sigma}(\mathbf{x}) \cdot \mathbf{n}_{i} & \leq 0, \forall \mathbf{n}_{i} \\
\llbracket u_{n}(\mathbf{x}) \rrbracket_{i}\left(\mathbf{n}_{i} \cdot \boldsymbol{\sigma}(\mathbf{x}) \cdot \mathbf{n}_{i}\right) & =0
\end{aligned}\right.
$$

where $\sigma$ is the local equilibrated stress field within the REV.

Finally, uniform stress boundary conditions are considered on the boundary in order to take advantage of fracture-mechanics based solutions, that is on any point $\mathbf{x}$ of $\partial \mathcal{A}$ with outward unit normal $\mathbf{v}$

$$
\sigma(\mathbf{x}) \cdot \mathbf{v}(\mathbf{x})=\Sigma \cdot \mathbf{v}(\mathbf{x})
$$

where $\boldsymbol{\Sigma}$ denotes the macroscopic stress tensor. 


\section{Homogenization procedure}

In addition to the assumption of a dilute concentration of microcracks, derivation of the thermodynamic potential $W$ (free energy function of macroscopic strain $\mathbf{E}$ ) results essentially from the following important modelling considerations:

- the decomposition of the elementary problem $\mathcal{P}$ (for a single microcracks family with normal $\mathbf{n}$ ) introduced by Andrieux et al. (1986): on the one hand, the homogeneous orthotropic material $\mathcal{P}^{(1)}$ subjected to boundary conditions and, on the other hand, the self-equilibrated fields $\mathcal{P}^{(2)}$

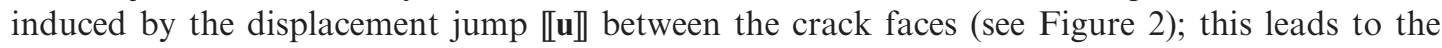
expression of the overall free energy as function of two scalar kinematic variables $\beta=\mathcal{N} \int_{\omega^{+}} \llbracket u_{n}(\mathbf{x}) \rrbracket d x$ and $\gamma=\mathcal{N} \int_{\omega^{+}} \llbracket u_{t}(\mathbf{x}) \rrbracket d x$, respectively, related to the normal and tangential average displacement jumps on the crack faces; such decomposition is crucial for the representation of unilateral effects since the microcracks contribution can be distinguished whether they are open $(\beta>0)$ or closed $(\beta=0)$;

- the application of the Hill lemma (Christensen, 1979; Hashin, 1983; Hill, 1965) in the context of cracked bodies (Telega, 1990); this question is of main importance for closed microcracks within anisotropic materials since $W$ cannot be reduced in the general case to the macroscopic elastic energy $\frac{1}{2} \mathbf{\Sigma}: \mathbf{E}$; indeed, for non-cubic (and obviously non-isotropic) symmetry of the matrix or when microcracks are not parallel to the orthotropic axes, tangential displacement discontinuity induces some non-negligible gap in the energy expression (Goidescu et al, 2013b);

- the introduction of basic solutions of anisotropic elasticity theory to derive expressions of the crack displacement jumps (Horii and Nemat-Nasser, 1983; Lekhnitskii, 1963; Mauge and Kachanov, 1994; Tsukrov and Kachanov, 2000); in particular, the initial anisotropy may induce a direct coupling between the normal and tangential cracking modes, especially again when the crack orientation does not coincide with the orthotropy axes;

- similar to Andrieux et al. (1986), the analysis of reversible conditions finally provides the expression of the kinematic variables as functions of the macroscopic strain $\mathbf{E}$ and of the widely used crack density parameter $d=\mathcal{N} R^{2}$ (Budiansky and O'Connel, 1976).

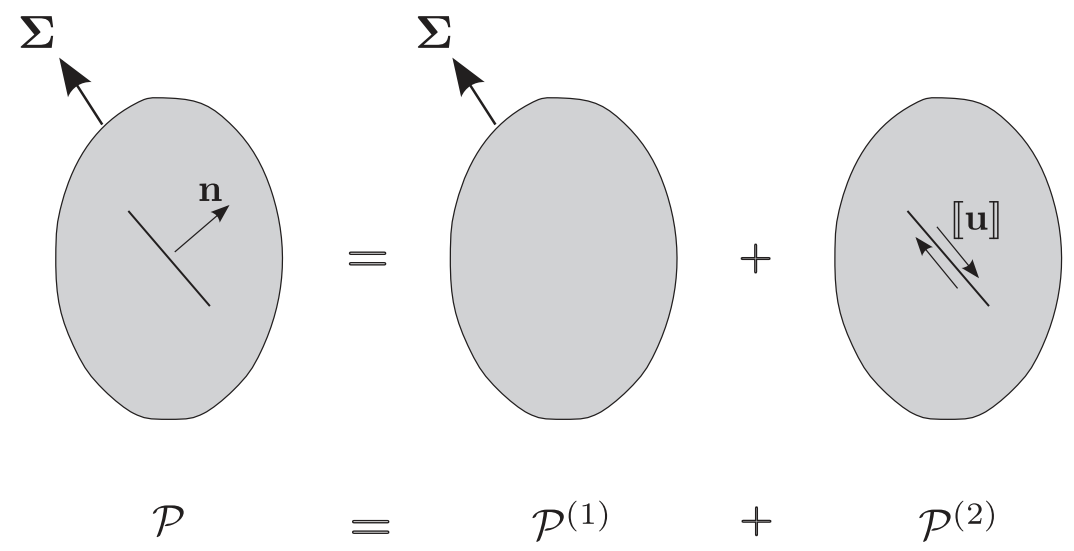

Figure 2. Decomposition of the considered homogenization problem. 


\section{Free energy of the microcracked material}

According to these points, Goidescu et al. (2013b) obtain the following closed-form expression of the overall free energy of the microcraked medium

$$
W=W_{0}+\sum_{i=1}^{N} d_{i}\left[\begin{array}{l}
c_{1}^{(i)} t^{2} \mathbf{E}+c_{2}^{(i)} \operatorname{tr}^{2}(\mathbf{E} \cdot \mathbf{A})+c_{3}^{(i)} \operatorname{tr} \mathbf{E} t r(\mathbf{E} \cdot \mathbf{A}) \\
+c_{4}^{(i)} \operatorname{tr}^{2}\left(\mathbf{E} \cdot \mathbf{n}_{i} \otimes \mathbf{n}_{i}\right)+c_{5}^{(i)} \operatorname{tr} \mathbf{E} \operatorname{tr}\left(\mathbf{E} \cdot \mathbf{n}_{i} \otimes \mathbf{n}_{i}\right) \\
+c_{6}^{(i)} \operatorname{tr}\left(\mathbf{E} \cdot \mathbf{E} \cdot \mathbf{n}_{i} \otimes \mathbf{n}_{i}\right) \\
+c_{9}^{(i)} \operatorname{tr} \mathbf{E} \operatorname{tr}\left(\mathbf{E} \cdot \mathbf{n}_{i} \otimes \mathbf{n}_{i} \cdot \mathbf{A}\right)+c_{8}^{(i)} \operatorname{tr}(\mathbf{E} \cdot \mathbf{A}) \operatorname{tr}\left(\mathbf{E} \cdot \mathbf{E} \cdot \mathbf{n}_{i} \otimes \mathbf{n}_{i} \otimes \mathbf{A}\right) \\
+c_{10}^{(i)} \operatorname{tr}\left(\mathbf{E} \cdot \mathbf{n}_{i} \otimes \mathbf{n}_{i}\right) \operatorname{tr}\left(\mathbf{E} \cdot \mathbf{n}_{i} \otimes \mathbf{n}_{i} \cdot \mathbf{A}\right)
\end{array}\right]
$$

with $W_{0}$ the free energy of the virgin material

$$
W_{0}=\frac{1}{2} ; \mathbf{E}: \mathbb{C}^{0}: \mathbf{E}=\frac{a_{1}}{2} \operatorname{tr}^{2} \mathbf{E}+\frac{a_{2}}{2} \operatorname{tr}(\mathbf{E} \cdot \mathbf{E})+\frac{a_{3}}{2} t r^{2}(\mathbf{E} \cdot \mathbf{A})+a_{4} \operatorname{tr} \mathbf{E} t r(\mathbf{E} \cdot \mathbf{A})
$$

and $\left\{c_{p}^{(i)}\right\}_{p=1,10}$ scalar coefficients that explicitly depend on the virgin properties (that is on the four engineering moduli) and on the microcracks orientation with respect to orthotropy (see Appendix 1). Generally speaking, the function $W$ is positively homogeneous of degree two with respect to $\mathbf{E}$, linear in the crack density vector $\mathbf{d}=\left(d_{i}\right)_{i=1, N}\left(d_{i}=\mathcal{N}_{\mathrm{i}} l_{i}^{2}\right.$, the density of each family of parallel microcracks with mean length $2 l_{i}$ and number $\mathcal{N}_{\mathrm{i}}$ per unit surface) and radially symmetric with respect to $\mathbf{n}_{i}$. The potential (6) depends on trace invariants which ensure its objectivity. The fact that the expression is not the most general one according to the theory of invariants (see for instance, recent works of Thionnet and Martin, 2006) must be viewed as a positive and a decisive contribution of micromechanics which allows then to define qualitatively (i.e. necessary invariants) and quantitatively (i.e. coefficients expression) the thermodynamic potential corresponding to the considered materials microstructure.

Orientational aspects are explicitly introduced by means of coupled invariants of tensor A (describing the primary orthotropy of the matrix) and normals $\mathbf{n}_{i}$ to the cracks (accounting for the microcracks-induced anisotropy). As discussed in Goidescu et al. (2013b), various interaction modes between anisotropies are possibly addressed by this way: an isotropic-like coupling that preserves the initial orthotropy of the material, together with an anisotropic coupling leading to a complex resulting symmetry if microcracks orientation differs from orthotropic axes. As an illustration, Figure 3 provides the distribution of the elongation modulus $L(\mathbf{m})$ ( $\mathbf{m}$ a unit vector) of a $2 \mathrm{D}$ $\mathrm{SiC}-\mathrm{SiC}$ composite studied by Aubard (1995) and weakened by a single set of parallel microcracks. Engineering constants in the orthotropic axes are $E_{1}=320 \mathrm{GPa}, E_{2}=170 \mathrm{GPa}, v_{12}=0.18$ and $G_{12}=90 \mathrm{GPa}$. This figure illustrates two orientation cases for the defects unit normal $\mathbf{n}$. When microcracking stands along symmetry axes $\left(\mathbf{n}=\mathbf{e}_{2}\right.$ in Figure $\left.3 \mathrm{a}\right)$, damage induces an orthotropic degradation of properties in the same axes of the virgin material (isotropic-like coupling); on the 

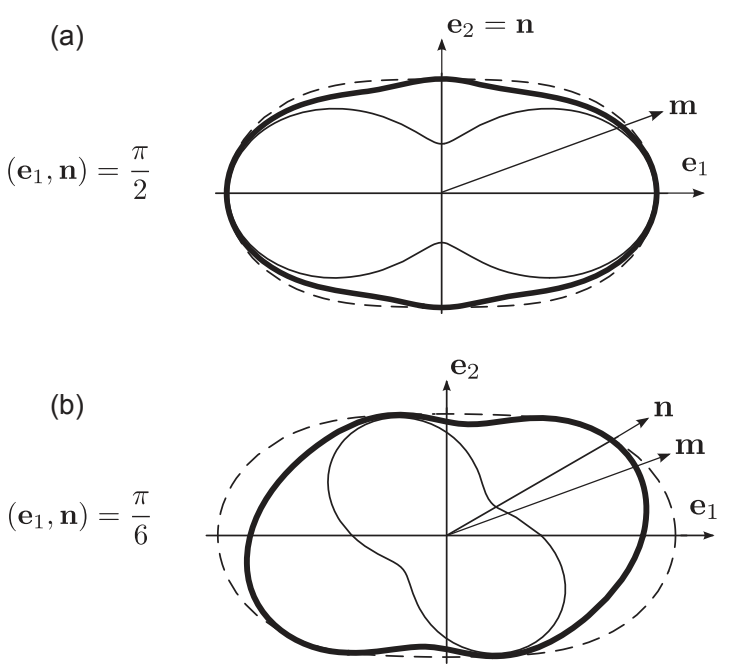

Figure 3. Roses of the generalized elongation modulus $L(\mathbf{m})(\mathrm{GPa})$ of a $\mathrm{SiC}-\mathrm{SiC}$ composite weakened by a single array of microcracks of unit normal $\mathbf{n}$ and density $d=0$. I. (a) $\left(\mathbf{e}_{1}, \mathbf{n}\right)=\pi / 2$ and (b) $\left(\mathbf{e}_{1}, \mathbf{n}\right)=\pi / 6$. - - -: virgin material; - open state of microcracks, — : closed state of microcracks.

contrary, an off-axis damage ( $\mathbf{n} \neq\left\{\mathbf{e}_{1}, \mathbf{e}_{2}\right\}$ in Figure $3 \mathrm{~b}$ ) leads to a complex resulting anisotropy, governed both by the initial orthotropy and by the orientation of the defects.

Regarding the damage contribution, the main originality of the energy expression (6) is to account for both open and closed microcracks. Indeed, coefficients $\left\{c_{p}^{(i)}\right\}_{p=1,10}$ take a different value according to the status of the $i$ th family of microcracks (see details in Appendix 1):

- $\left\{c_{p}^{(i)}\left(\mathbb{C}^{0}, \mathbf{n}_{i}, \mathbf{A}\right)\right\}_{p=1,10}=\left\{c_{p}^{\text {open }}\left(\mathbb{C}^{0}, \mathbf{n}_{i}, \mathbf{A}\right)\right\}_{p=1,10}$ in their open state, that is when $g\left(\mathbf{E}, \mathbf{n}_{i}, \mathbf{A}\right)>0$ (equations 25),

- $\left\{c_{p}^{(i)}\left(\mathbb{C}^{0}, \mathbf{n}_{i}, \mathbf{A}\right)\right\}_{p=1,10}=\left\{c_{p}^{c l o s}\left(\mathbb{C}^{0}, \mathbf{n}_{i}, \mathbf{A}\right)\right\}_{p=1,10}$ in their closed state, that is when $g\left(\mathbf{E}, \mathbf{n}_{i}, \mathbf{A}\right) \leq 0$ (equations 26).

Function $g$, that corresponds here to the opening-closure characteristic function, derives from the cancellation of the normal jump displacement at the closure of microcraks $(\beta=0)$

$$
g\left(\mathbf{E}, \mathbf{n}_{i}, \mathbf{A}\right)=\eta_{1}^{(i)} \operatorname{tr}\left(\mathbf{E} \cdot \mathbf{n}_{i} \otimes \mathbf{n}_{i}\right)+\eta_{2}^{(i)} \operatorname{tr} \mathbf{E}+\eta_{3}^{(i)} \operatorname{tr}(\mathbf{E} \cdot \mathbf{A})+\eta_{4}^{(i)} \operatorname{tr}\left(\mathbf{E} \cdot \mathbf{n}_{i} \otimes \mathbf{n}_{i} \cdot \mathbf{A}\right)
$$

with coefficients $\left\{\eta_{p}^{(i)}\right\}_{p=1,4}$ depending also on the virgin properties and on the microcracks orientation with respect to orthotropy (Appendix 1). Interaction between initial and induced anisotropies affects then both the kind of resulting material symmetry and also the microcracks opening/closure status for a given strain state $\mathbf{E}$ (due to coupling terms of $\mathbf{A}$ and $\mathbf{n}_{i}$ in (6) and (8)). Through the different value of coefficients $\left\{c_{p}^{(i)}\right\}_{p=1,10}$, the status of microcracks influences subsequently the degradation intensity. Generally speaking, one notes some recovery of the degraded properties at the closure of microcracks. 
As shown in Figure 3, we clearly observe a total recovery to its initial value of the elongation modulus in the direction normal to cracks $L(\mathbf{n})$ when cracks orientation coincides with the orthotropic axes. The off-axis case is much more complex with a major recovery for directions $\mathbf{m}$ close to the normal $\mathbf{n}$ to the defects (see also complementary analyses of Goidescu et al., 2013b).

To conclude on this part, some important points need to be underlined regarding this formulation:

- its mathematical admissibility: we should emphasize the fact that the free energy function (6) obtained here is continuously differentiable; indeed, the quadratic form of the stiffness jump at the opening-closure transition satisfies in all cases the continuity conditions established by Curnier et al. (1995) and Cormery and Welemane (2010); compared to existing formulations mostly affected by inconsistencies regarding that point, this is a very remarkable aspect;

- its micromechanics background that provides a physical basis to the formulation: an outstanding example is the definition of the opening-closure criterion that comes from the description of jump displacements at the defects scale; accordingly, this leads to a much more general expression than the phenomenological criterion $\mathbf{n} \cdot \mathbf{E} \cdot \mathbf{n}=0$ classically used in the literature and restricted to the normal strain (for instance, Halm et al., 2002; Maire and Chaboche, 1997); we can note also that the recovery phenomenon at the closure of microcracks is quite complex, micromechanics offers then a relevant help for its description (Welemane and Cormery, 2002, 2003);

- its general and open nature: indeed, the formulation (6) fully contains the isotropic case (for which $a_{3}=a_{4}=0$ ) obtained previously by Andrieux et al. (1986); it can also be applied for any 2D initially orthotropic material (see for instance application on a sedimentary rock by Levasseur et al., 2013).

\section{Model formulation}

Based on the recalled micromechanical background, we now intend to derive the new model for anisotropic damage in 2D initially orthotropic materials coupled with unilateral effects. Considering a single dissipative mechanism, namely the growth of frictionless and non-interacting microcracks, this strain-based formulation is developed within the thermodynamics framework for irreversible processes.

\section{Damage variables}

In relation with the previous homogenization approach, the model uses a discrete damage representation based on a set of scalar variables $\mathbf{d}=\left(d_{i}\right)_{i=1, N}$ (microcracks density parameter) associated to a finite number of microcracks systems. Contrary to existing formulations that consider distinct damage parameters for open and for closed microcracks (see for instance, Ladevéze et al., 1994), the set of internal variables is here simply related to the extent (density) of microcracks whatever their status. Regarding the microcracks systems, their number $N$ and orientations constitute basic data of the model. Under complex loading paths, an important number of microcracks systems can be activated. In this paper, we have considered $N=60$ families exhibiting a uniform orientational distribution described on Figure 4

$$
\left(\mathbf{n}_{i}, \mathbf{n}_{i+1}\right)=\frac{\pi}{N}, \quad \forall i \in[1, N]
$$




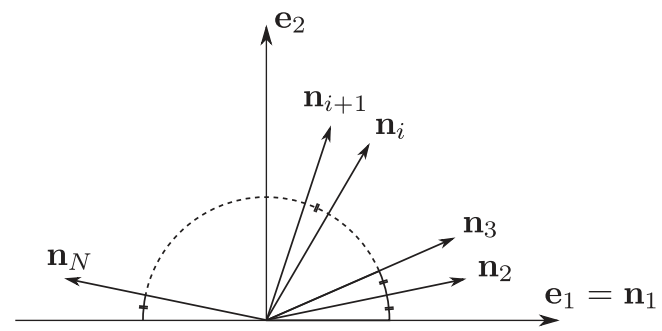

Figure 4. Spatial orientation distribution of the sets of parallel microcracks.

This choice is made in order to provide a reasonable determination of the damage density distribution (there is a system each $3^{\circ}$ ). Yet, a continuous damage representation would require either an infinite number of systems or a reduced number of equivalent systems based on Gauss type numerical integration (Bazant and Oh, 1986; Carol et al., 1992). In the latter case, the approach would then become an 'integrated discrete' damage representation one. Regarding the definition of equivalent systems, some works exist for isotropic materials (Bargellini et al., 2007; Zhu, 2006), but the question remains still open for initially anisotropic materials, in particular when microcracks closure effects are taken into account.

\section{State laws}

The continuity of class $C^{1}$ of the free energy ensures the existence and continuity $C^{0}$ of the partial derivatives of $W$, namely the macroscopic stress $\Sigma=\frac{\partial W}{\partial \mathbf{E}}$ and the thermodynamic forces $F^{d_{i}}=-\frac{\partial W}{\partial d_{i}}$ for every $i \in[1, N]$ associated to the microcracks systems

$$
\left.\begin{array}{rl}
\mathbf{\Sigma}(\mathbf{E}, \mathbf{d})=a_{1}(\operatorname{tr} \mathbf{E}) \mathbf{I}+a_{2} \mathbf{E}+2 a_{3} \operatorname{tr}(\mathbf{E} \cdot \mathbf{A}) \mathbf{A}+a_{4}[\operatorname{tr}(\mathbf{E} \cdot \mathbf{A}) \mathbf{I}+(\operatorname{tr} \mathbf{E}) \mathbf{A}] \\
+\sum_{i=1}^{N} d_{i}\left[\begin{array}{l}
2 c_{1}^{(i)}(\operatorname{tr} \mathbf{E}) \mathbf{I}+2 c_{2}^{(i)} \operatorname{tr}(\mathbf{E} \cdot \mathbf{A}) \mathbf{A} \\
+c_{3}^{(i)}[\operatorname{tr}(\mathbf{E} \cdot \mathbf{A}) \mathbf{I}+(\operatorname{tr} \mathbf{E}) \mathbf{A}] \\
+2 c_{4}^{(i)} \operatorname{tr}\left(\mathbf{E} \cdot \mathbf{n}_{i} \otimes \mathbf{n}_{i}\right) \mathbf{n}_{i} \otimes \mathbf{n}_{i} \\
+c_{5}^{(i)}\left[\operatorname{tr}\left(\mathbf{E} \cdot \mathbf{n}_{i} \otimes \mathbf{n}_{i}\right) \mathbf{I}+(\operatorname{tr} \mathbf{E}) \mathbf{n}_{i} \otimes \mathbf{n}_{i}\right] \\
+c_{6}^{(i)}\left(\mathbf{E} \cdot \mathbf{n}_{i} \otimes \mathbf{n}_{i}+\mathbf{n}_{i} \otimes \mathbf{n}_{i} \cdot \mathbf{E}\right) \\
\operatorname{tr}\left(\mathbf{E} \cdot \mathbf{n}_{i} \otimes \mathbf{n}_{i} \cdot \mathbf{A}\right) \mathbf{I} \\
+\frac{1}{2}(\operatorname{tr} \mathbf{E})\left(\mathbf{n}_{i} \otimes \mathbf{n}_{i} \cdot \mathbf{A}+\mathbf{A} \cdot \mathbf{n}_{i} \otimes \mathbf{n}_{i}\right)
\end{array}\right] \\
+c_{8}^{(i)}\left[\operatorname{tr}\left(\mathbf{E} \cdot \mathbf{n}_{i} \otimes \mathbf{n}_{i}\right) \mathbf{A}+\operatorname{tr}(\mathbf{E} \cdot \mathbf{A}) \mathbf{n}_{i} \otimes \mathbf{n}_{i}\right] \\
+c_{9}^{(i)}\left[\begin{array}{l}
\operatorname{tr}\left(\mathbf{E} \cdot \mathbf{n}_{i} \otimes \mathbf{n}_{i} \cdot \mathbf{A}\right) \mathbf{A} \\
+\frac{1}{2} \operatorname{tr}(\mathbf{E} \cdot \mathbf{A})\left(\mathbf{n}_{i} \otimes \mathbf{n}_{i} \cdot \mathbf{A}+\mathbf{A} \cdot \mathbf{n}_{i} \otimes \mathbf{n}_{i}\right)
\end{array}\right] \\
+c_{10}^{(i)}\left[\begin{array}{l}
\operatorname{tr}\left(\mathbf{E} \cdot \mathbf{n}_{i} \otimes \mathbf{n}_{i} \cdot \mathbf{A}\right) \mathbf{n}_{i} \otimes \mathbf{n}_{i} \\
+\frac{1}{2} \operatorname{tr}\left(\mathbf{E} \cdot \mathbf{n}_{i} \otimes \mathbf{n}_{i}\right)\left(\mathbf{n}_{i} \otimes \mathbf{n}_{i} \cdot \mathbf{A}+\mathbf{A} \cdot \mathbf{n}_{i} \otimes \mathbf{n}_{i}\right)
\end{array}\right]
\end{array}\right]
$$


and

$$
F^{d_{i}}(\mathbf{E}, \mathbf{d})=-\left[\begin{array}{l}
c_{1}^{(i)} \operatorname{tr}^{2} \mathbf{E}+c_{2}^{(i)} t^{2}(\mathbf{E} \cdot \mathbf{A})+c_{3}^{(i)} \operatorname{tr} \mathbf{E} t r(\mathbf{E} \cdot \mathbf{A}) \\
+c_{4}^{(i)} \operatorname{tr}\left(\mathbf{E} \cdot \mathbf{n}_{i} \otimes \mathbf{n}_{i}\right)+c_{5}^{(i)} \operatorname{tr} \mathbf{E} \operatorname{tr}\left(\mathbf{E} \cdot \mathbf{n}_{i} \otimes \mathbf{n}_{i}\right) \\
+c_{6}^{(i)} \operatorname{tr}\left(\mathbf{E} \cdot \mathbf{E} \cdot \mathbf{n}_{i} \otimes \mathbf{n}_{i}\right) \\
+c_{7}^{(i)} \operatorname{tr} \mathbf{E} \operatorname{tr}\left(\mathbf{E} \cdot \mathbf{n}_{i} \otimes \mathbf{n}_{i} \cdot \mathbf{A}\right) \\
+c_{8}^{(i)} \operatorname{tr}(\mathbf{E} \cdot \mathbf{A}) \operatorname{tr}\left(\mathbf{E} \cdot \mathbf{n}_{i} \otimes \mathbf{n}_{i}\right) \\
+c_{9}^{(i)} \operatorname{tr}(\mathbf{E} \cdot \mathbf{A}) \operatorname{tr}\left(\mathbf{E} \cdot \mathbf{n}_{i} \otimes \mathbf{n}_{i} \cdot \mathbf{A}\right) \\
+c_{10}^{(i)} \operatorname{tr}\left(\mathbf{E} \cdot \mathbf{n}_{i} \otimes \mathbf{n}_{i}\right) \operatorname{tr}\left(\mathbf{E} \cdot \mathbf{n}_{i} \otimes \mathbf{n}_{i} \cdot \mathbf{A}\right)
\end{array}\right]
$$

These state laws are then clearly affected by the opening-closure status of microcracks through coefficients $\left\{c_{p}^{(i)}\right\}_{p=1,10}$, while remaining continuous at the microcrack activation-deactivation point. The derivation of the macroscopic stress (10) gives also rise to the overall stiffness tensor $\mathbb{C}=\frac{\partial \Sigma}{\partial \mathbf{E}}$

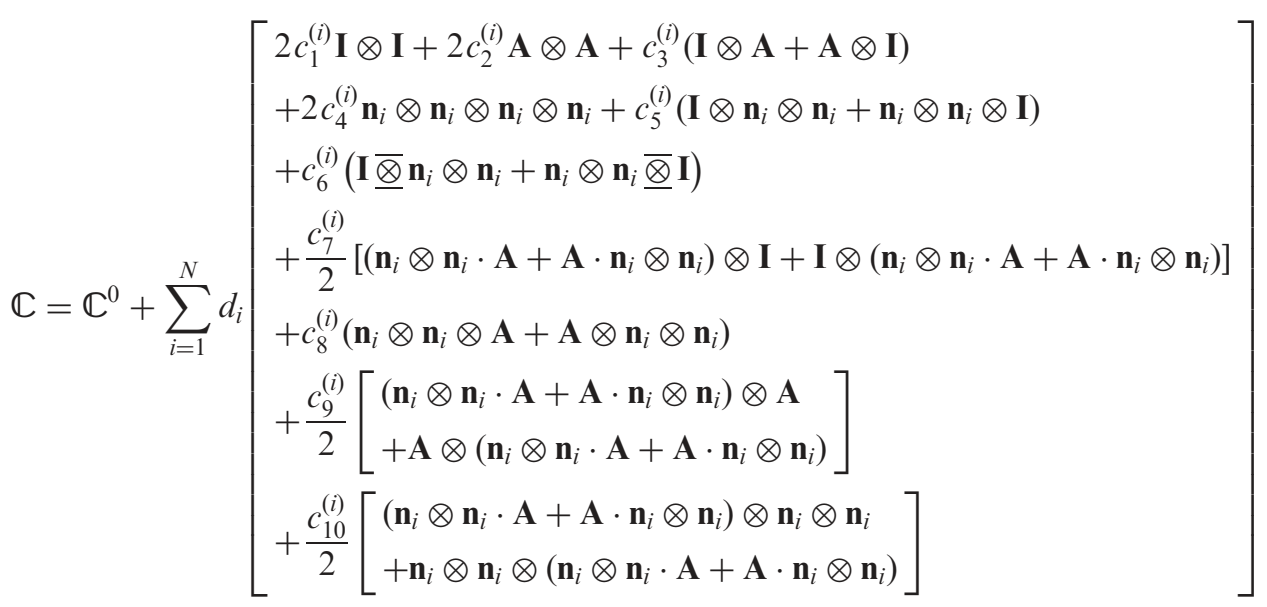

According to the specific unilateral behaviour of microcracks, this fourth-order tensor is defined on the strict domain of opening and closure of the defects $\mathcal{S}=\left\{(\mathbf{E}, \mathbf{d}), g\left(\mathbf{E}, \mathbf{n}_{i}, \mathbf{A}\right) \neq 0, \quad \forall i \in[1, N]\right\}$.

\section{Damage evolution law}

If ductile damage models (such as Gurson, 1977 for instance) justify also their evolution laws from micromechanical analyses, this option cannot be used for the moment regarding microcracking phenomena. Accordingly, the evolution process is described here through classical thermodynamical arguments.

Since orientations $\mathbf{n}_{i}$ are fixed, we assume that microcracks can only propagate along their plane. This clearly simplifies the numerical implementation of the model, while allowing the representation of complex damage developments owing to the consideration of an important number $N$ of systems. Indeed, the model can account for the creation and growth of microcracks not guided by the 
microstructure (when $\mathbf{n}_{i} \neq\left(\mathbf{e}_{1}, \mathbf{e}_{2}\right)$ ) induced by off-axis loads and also for consequences of branching phenomena by activating several appropriate systems. Damage growth is also supposed to be progressive and rate independent. In agreement with the dilute scheme used before, the damage evolution law of all microcracks families exhibits the same form but remains independent for each system.

More precisely, the framework of generalized standard materials is chosen to ensure in all cases the satisfaction of the second principle of thermodynamics (Germain et al., 1983; Marigo, 1981). We postulate the existence of a scalar dissipation potential $\mathcal{D}$ in the form

$$
\mathcal{D}\left(\dot{d}_{i}, d_{i}\right)=\mathcal{G}\left(d_{i}\right) \dot{d}_{i}
$$

with $\mathcal{G}$ a strictly positive scalar function that can be related to the surface energy of the Fracture Mechanics. An affine expression suggested by Marigo (1985) is considered here for this function

$$
\mathcal{G}\left(d_{i}\right)=k_{0}\left(1+\eta d_{i}\right)
$$

where $k_{0}$ and $\eta$ are two strictly positive scalar coefficients depending on the material. The intrinsic dissipation $\Phi_{i}=F^{d_{i}} \dot{d}_{i}=\mathcal{D}\left(\dot{d}_{i}, d_{i}\right)$ of the $i$ th microcracks system is then proportional to the rate of the density $\dot{d}_{i}$ and increases with the value of $d_{i}$. Again, in the present dilute case, the global intrinsic dissipation $\Phi$ is obtained by the summation of the individual contributions of all the microcracks systems, $\Phi=\sum_{i=1}^{N} \Phi_{i}$.

Combining (13) with the normality rule provides first the damage criterion written in the thermodynamic forces space

$$
f\left(F^{d_{i}}, d_{i}\right)=F^{d_{i}}-\mathcal{G}\left(d_{i}\right)
$$

associated with the reversibility convex domain

$$
\mathcal{C}_{i}\left(d_{i}\right)=\left\{F^{d_{i}}, f\left(F^{d_{i}}, d_{i}\right) \leq 0\right\}
$$

for the $i$ th family of microcracks. Since $F^{d_{i}}$ depends on the opening-closure status of the defects, the criterion (15) and the domain $\mathcal{C}_{i}$ are different whether this system is opened or closed. For a number $N$ of microcracks, note that the global reversibility domain $\mathcal{C}$ of the material is given by the intersection of indidual ones, $\mathcal{C}(\mathbf{d})=\cap_{i=1}^{N} \mathcal{C}\left(d_{i}\right)$.

Regarding the evolution law, one gets

$$
\left\{\begin{array}{l}
\dot{d}_{i}=\Lambda_{i} \frac{\partial f}{\partial F^{d_{i}}}=\Lambda_{i} \\
\Lambda_{i}=0, \quad \text { if } f\left(F^{d_{i}}, d_{i}\right) \leq 0, \dot{f}\left(F^{d_{i}}, d_{i}\right)<0 \\
\Lambda_{i}>0, \quad \text { if } f\left(F^{d_{i}}, d_{i}\right)=0, \dot{f}\left(F^{d_{i}}, d_{i}\right)=0
\end{array} \quad \forall i \in[1, N]\right.
$$

From the classical Kuhn-Tucker condition $\dot{f}\left(F^{d_{i}}, d_{i}\right)=0$ and equations (14) and (15), the damage multiplier $\Lambda_{i}$ reads

$$
\Lambda_{i}=\left[\frac{\dot{F}^{d_{i}}}{k_{0} \eta}\right]^{+}=\left[\frac{1}{k_{0} \eta}\left(\frac{\partial F^{d_{i}}}{\partial \mathbf{E}}\right): \dot{\mathbf{E}}\right]^{+}, \quad \forall i \in[1, N]
$$

with $x^{+}=\sup \{0, x\}$ and $\frac{\partial F^{d_{i}}}{\partial \mathbf{E}}$ defined on the domain $\mathcal{S}$. 
The rate form of the damage model can be deduced from

$$
\begin{aligned}
\dot{\boldsymbol{\Sigma}}(\mathbf{E}, \mathbf{d})= & \dot{\mathbb{C}}(\mathbf{E}, \mathbf{d}): \mathbf{E}+\mathbb{C}(\mathbf{E}, \mathbf{d}): \dot{\mathbf{E}} \\
& =\left(\frac{\partial \mathbb{C}}{\partial \mathbf{E}}(\mathbf{E}, \mathbf{d}): \dot{\mathbf{E}}+\sum_{i=1}^{N} \frac{\partial \mathbb{C}}{\partial d_{i}}(\mathbf{E}, \mathbf{d}) \dot{d}_{i}\right): \mathbf{E}+\mathbb{C}(\mathbf{E}, \mathbf{d}): \dot{\mathbf{E}}
\end{aligned}
$$

Yet, tensor $\mathbb{C}$ depends on the opening-closure effects through $\left\{c_{p}^{(i)}\right\}_{p=1,10}$ that take different values for open or closed microcracks. The derivative appearing in equation (19) is then not straightforward and can only be expressed in a closed-form for evolution processes that keep the microcracks status (either open or closed). In this case, we obtain

$$
\dot{\Sigma}=\mathbb{L}(\mathbf{E}, \mathbf{d}): \dot{\mathbf{E}}
$$

since

$$
\frac{\partial \mathbb{C}}{\partial d_{i}}: \mathbf{E}=-\frac{\partial F^{d_{i}}}{\partial \mathbf{E}}, \quad \forall i \in[1, N]
$$

The tangent operator $\mathbb{L}(\mathbf{E}, \mathbf{d})$ is defined on the domain $\mathcal{S}$ with the following expression

$$
\mathbb{L}(\mathbf{E}, \mathbf{d})=\left\{\begin{array}{cl}
\mathbb{C}(\mathbf{E}, \mathbf{d}), & \text { if } f\left(F^{d_{i}}, d_{i}\right) \leq 0, \dot{f}\left(F^{d_{i}}, d_{i}\right)<0 \\
\mathbb{C}(\mathbf{E}, \mathbf{d})-\frac{1}{k_{0} \eta} \sum_{i=1}^{N} \frac{\partial F^{d_{i}}}{\partial \mathbf{E}} \otimes \frac{\partial F^{d_{i}}}{\partial \mathbf{E}}, & \text { if } f\left(F^{d_{i}}, d_{i}\right)=0, \dot{f}\left(F^{d_{i}}, d_{i}\right)=0
\end{array}\right\}
$$

Such fourth-order operator exhibits then the same symmetry as the elastic stiffness tensor.

\section{Computational aspects and numerical implementation}

The previous constitutive law has been implemented within the finite-element software ABAQUS standard by means of the user subroutine UMAT. The incremental procedure is based on a classical strain discretization of the loading path associated with a prediction-correction integration scheme. From the macroscopic strain $\mathbf{E}^{r}$ and damage variables $\mathbf{d}^{r}=\left(d_{i}^{r}\right)_{i=1, N}$ at the time $r$ and knowing the strain $\mathbf{E}^{r+1}=\mathbf{E}^{r}+\Delta \mathbf{E}$ at the time $r+1$, the local integration procedure follows two steps:

(1) Elastic prediction: we check that $F^{d_{i}}\left(\mathbf{E}^{r+1}\right) \in \mathcal{C}_{i}\left(d_{i}^{r}\right), \forall ; i \in[1, N]$; if yes, one has $\mathbf{d}^{r+1}=\mathbf{d}^{r}$;

(2) Damage correction: otherwise, that is $\exists j \in[1, N], ; F^{d_{j}}\left(\mathbf{E}^{r+1}\right) \notin \mathcal{C}_{j}\left(d_{j}^{r}\right)$, the density increase $\Delta d_{j}=d_{j}^{r+1}-d_{j}^{r}$ is provided by the condition $f\left(F^{d_{j}}\left(\mathbf{E}^{r+1}\right), d_{j}^{r+1}\right)=0$; contrary to elasto-plastic behaviour, such result can be obtained directly due to the form (15), namely

$$
\Delta d_{j}=\frac{f\left(F^{d_{j}}\left(\mathbf{E}^{r+1}\right), d_{j}^{r}\right)}{k_{0} \eta}
$$

From that, all damage variables can be updated $\mathbf{d}^{r+1}=\mathbf{d}^{r}+\Delta \mathbf{d}$ with $\Delta \mathbf{d}=\left(\Delta d_{i}\right)_{i=1, N}$. Note also that we have added some output data in order to know the opening-closure status of each family, and this will be illustrated in the results part. 


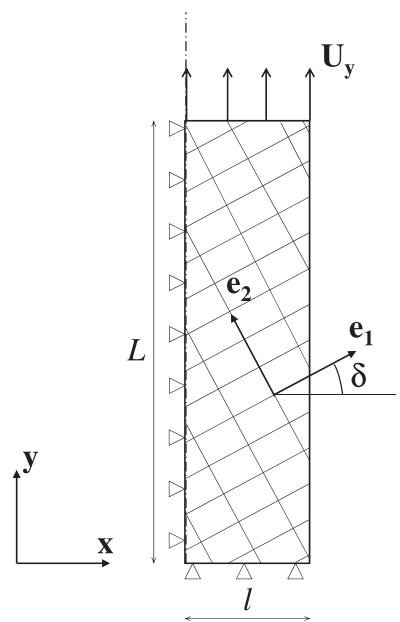

Figure 5. Numerical model $(I=12.5 \mathrm{~mm}, L=250 \mathrm{~mm})$.

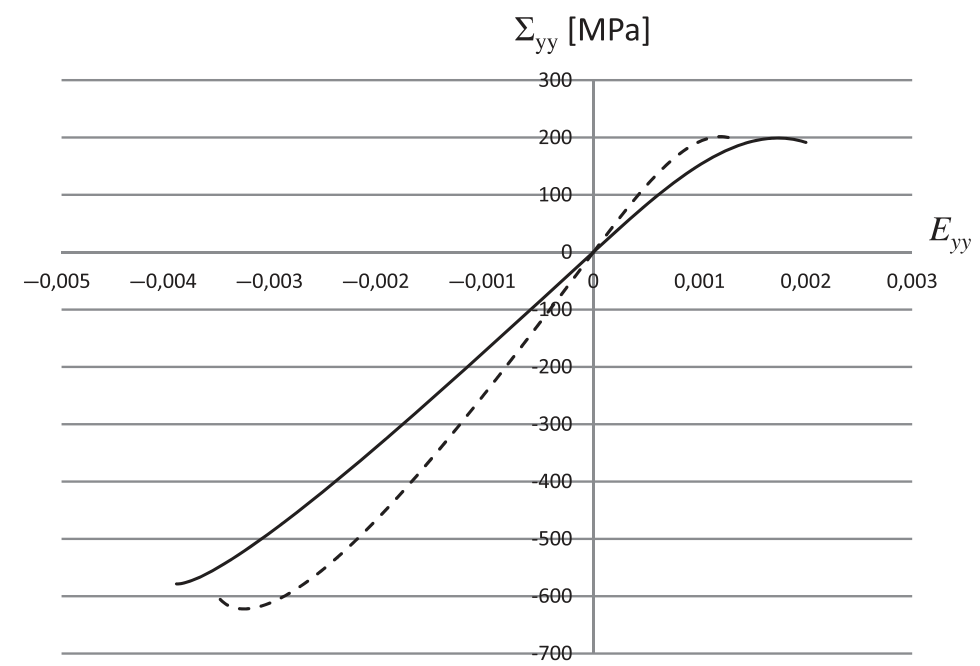

Figure 6. Axial stress-strain responses for uniaxial loads (tension and compression) and for axis (full line: $\delta=0^{\circ}$, $\mathbf{y}=\mathbf{e}_{2}$ ) and off-axis cases (dashed line: $\delta=45^{\circ}$ ).

\section{Analysis of the predictive ability of the formulation}

In this section, the proposed model will be used to simulate some classical loading paths on the brittle $\mathrm{SiC}-\mathrm{SiC}$ material studied in 'Free energy of the microcracked material' section. In addition to the four elastic constants $\left(E_{1}, E_{2}, v_{12}, G_{12}\right)$ in the initial orthotropy axes $\left(\mathbf{e}_{1}, \mathbf{e}_{2}\right)$, the model requires the identification of two constants $\left(k_{0}, \eta\right)$ involved in the description of the dissipative mechanisms. The latter may be determined from tensile tests along the principal directions of orthotropy: $k_{0}$ is 


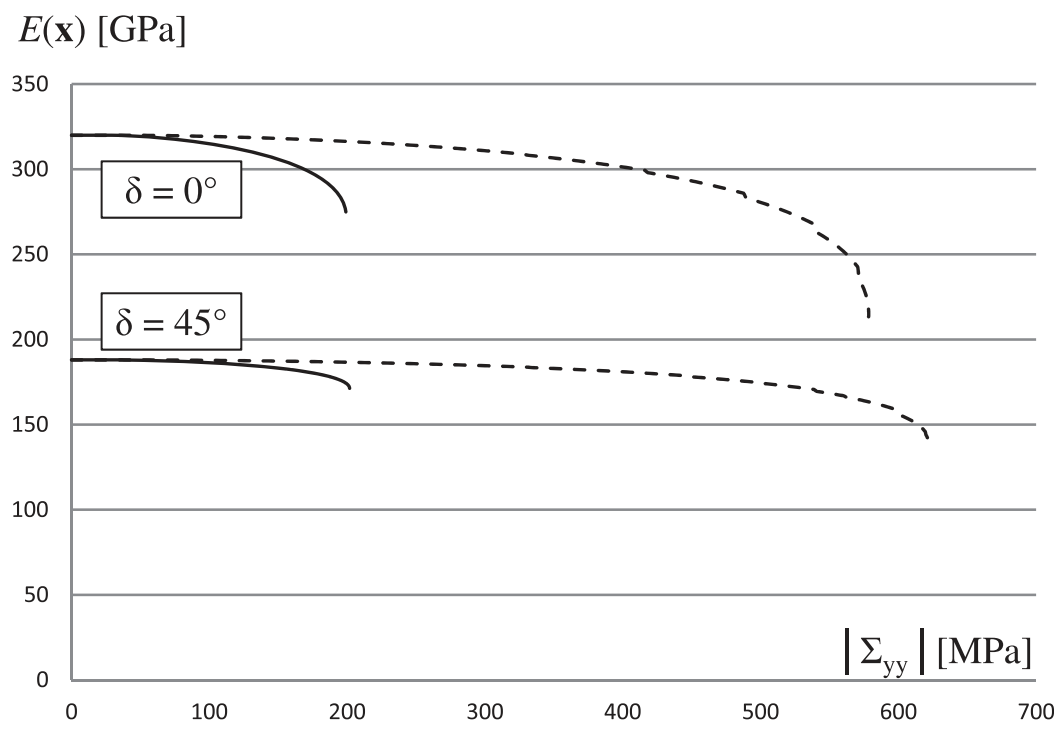

$E(\mathbf{y})[\mathrm{GPa}]$

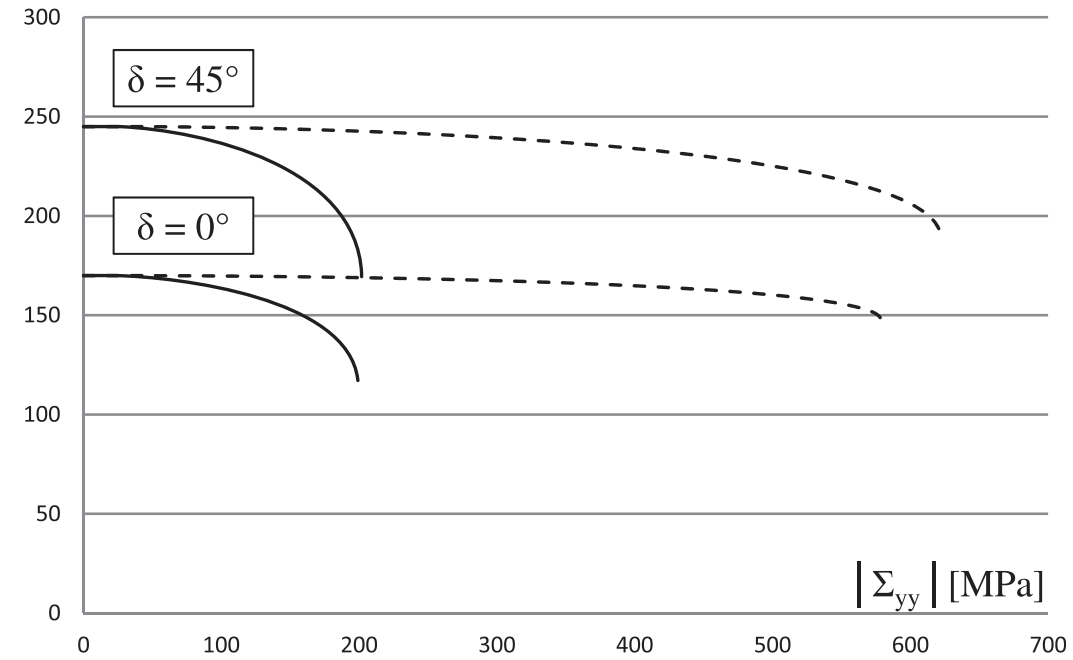

Figure 7. Evolution of effective Young moduli $E(\mathbf{x})$ and $E(\mathbf{y})$ according to the axial load $\boldsymbol{\Sigma}=\Sigma_{y y} \mathbf{y} \otimes \mathbf{y}$ (full line: tensile tests, $\Sigma_{y y}>0$; dashed line: compression tests, $\left.\Sigma_{y y}<0\right)$.

linked to the initiation of microcracks in the direction orthogonal to the load and $n$ is calibrated to capture the non-linearity of the axial stress-strain response (Goidescu, 2011). The following values are obtained from tests of Aubard (1995): $k_{0}=0.008 \mathrm{MPa}, \eta=70,000$.

In what follows, uniaxial loads along direction of unit vector $\mathbf{y}$ are presented, either under tensile or compressive load, and for axis $\left(\delta=\left(\mathbf{x}, \mathbf{e}_{1}\right)=\left(\mathbf{y}, \mathbf{e}_{2}\right)=0^{\circ}\right)$ and off-axis cases $\left(\delta \neq 0^{\circ}\right)$. For finite element simulations, we have used a 2D plane stress model with structured mesh (50 QUAD CPS4 


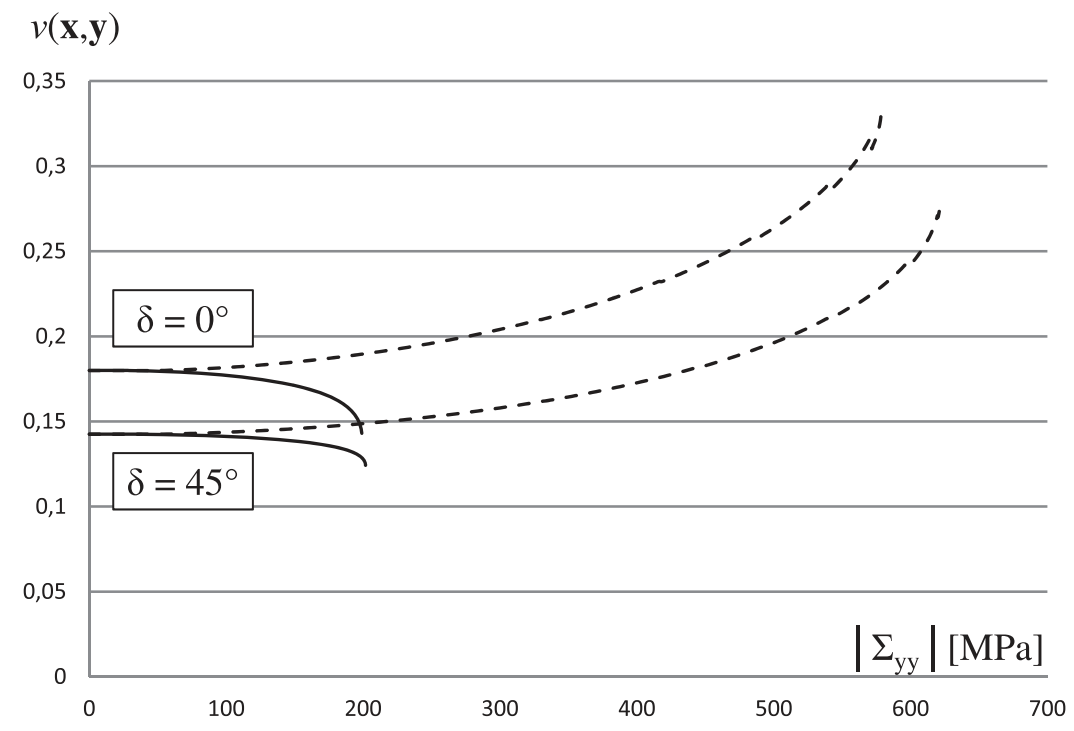

$G(\mathbf{x}, \mathbf{y})[\mathrm{GPa}]$

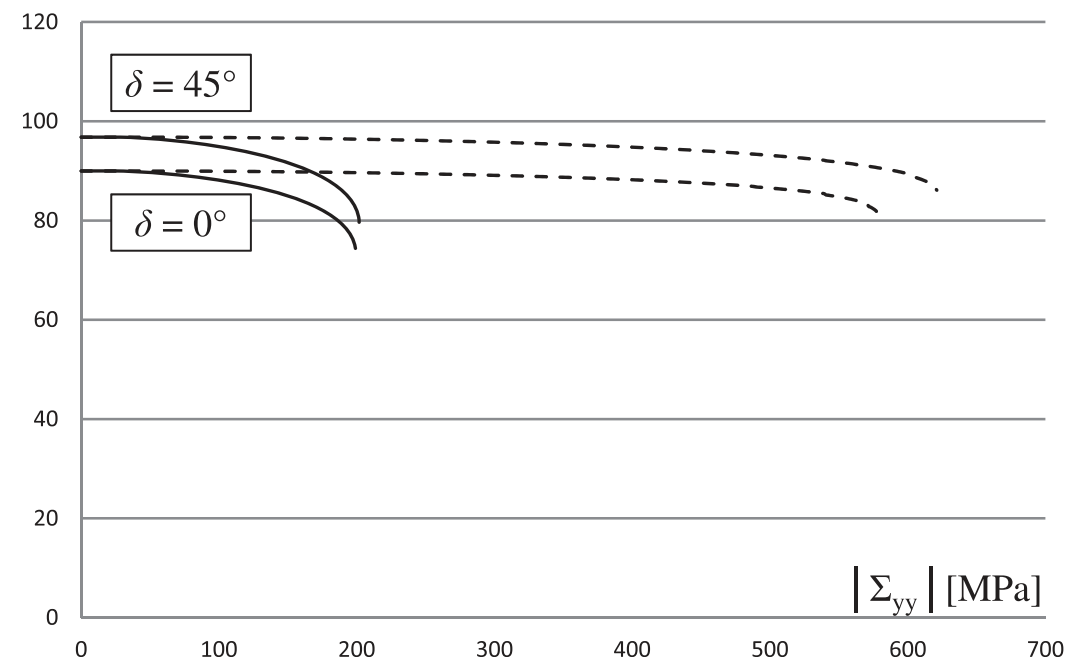

Figure 8. Evolution of effective Poisson ratio $v(\mathbf{x}, \mathbf{y})$ and shear modulus $G(\mathbf{x}, \mathbf{y})$ according to the axial load $\boldsymbol{\Sigma}=\Sigma_{y y} \mathbf{y} \otimes \mathbf{y}$ (full line: tensile tests, $\Sigma_{y y}>0$; dashed line: compression tests, $\Sigma_{y y}<0$ ).

elements); geometry, boundary conditions and loads (applied axial displacements) are provided in Figure 5.

First of all, the model is able to capture the damage-induced irreversible behaviour, both under tensile and compressive loads. The axial stress-strain response $\Sigma_{y y}-E_{y y}$ of the studied composite is provided in Figure 6. It exhibits from a given stage a non-linear part related to the degradation of elastic properties that depends both on the loading orientation (due to the interaction between 


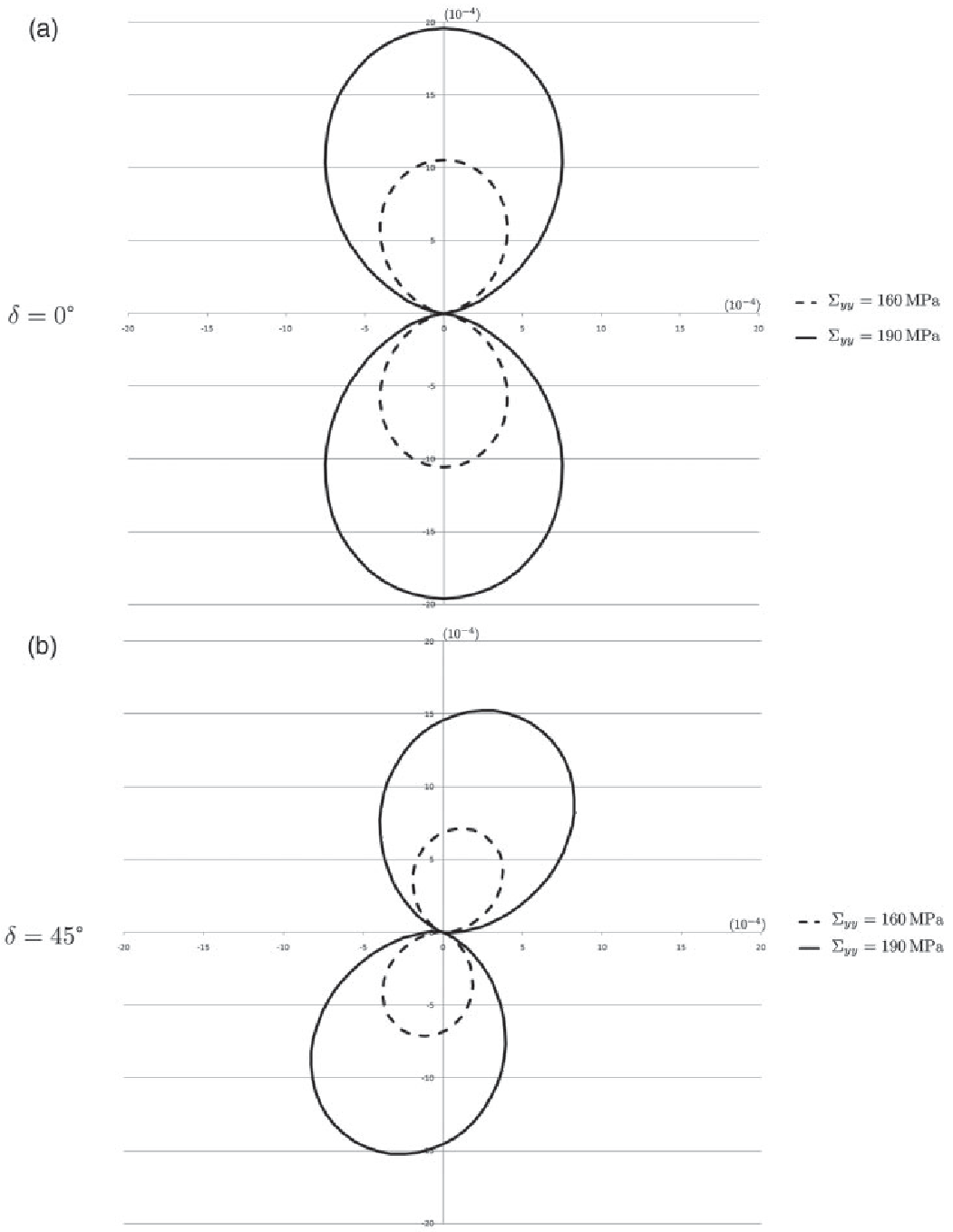

Figure 9. Roses of the density distribution in the frame $(\mathbf{x}, \mathbf{y})$ for tensile tests $\boldsymbol{\Sigma}=\Sigma_{y y} \mathbf{y} \otimes \mathbf{y}\left(\Sigma_{y y}>0\right)$ and two loading directions $\delta$. (a) $\delta=0^{\circ}$ and (b) $\delta=45^{\circ}$.

induced and initial anisotropies) and on the tensile or compressive nature of the load (due to the unilateral effects).

These consequences are also corroborated by the evolution of elastic properties with the load. Figures 7 and 8 show the effective elastic properties of the material, namely the Young moduli $E(\mathbf{x})$ and $E(\mathbf{y})$ related, respectively, to directions of unit vectors $\mathbf{x}$ and $\mathbf{y}$ and the Poisson ratio $v(\mathbf{x}, \mathbf{y})$ and shear modulus $G(\mathbf{x}, \mathbf{y})$ related to plane $(\mathbf{x}, \mathbf{y})$ defined by (Hayes, 1972)

$$
\begin{aligned}
E(\mathbf{x}) & =\left[\mathbf{x} \otimes \mathbf{x}: \mathbb{C}^{-1}: \mathbf{x} \otimes \mathbf{x}\right]^{-1}, \quad E(\mathbf{y})=\left[\mathbf{y} \otimes \mathbf{y}: \mathbb{C}^{-1}: \mathbf{y} \otimes \mathbf{y}\right]^{-1} \\
v(\mathbf{x}, \mathbf{y}) & =E(\mathbf{x})\left[\mathbf{x} \otimes \mathbf{x}: \mathbb{C}^{-1}: \mathbf{y} \otimes \mathbf{y}\right], \quad G(\mathbf{x}, \mathbf{y})=\left[4 ; \mathbf{x} \otimes \mathbf{y}: \mathbb{C}^{-1}: \mathbf{x} \otimes \mathbf{y}\right]^{-1}
\end{aligned}
$$




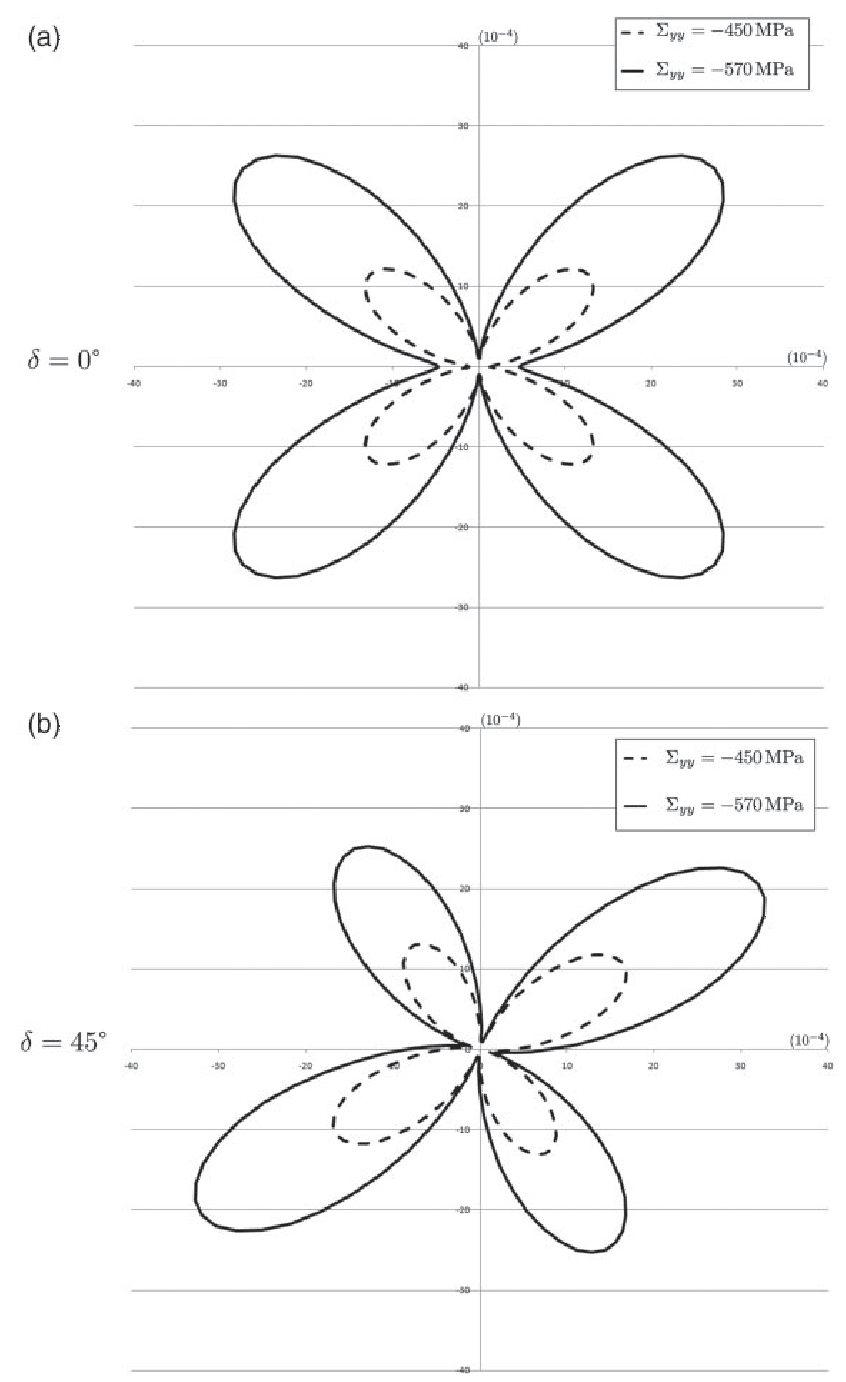

Figure 10. Roses of the density distribution in the frame $(\mathbf{x}, \mathbf{y})$ for compression tests $\boldsymbol{\Sigma}=\Sigma_{y y} \mathbf{y} \otimes \mathbf{y}\left(\Sigma_{y y}<0\right)$ and two loading directions $\delta$. (a) $\delta=0^{\circ}$ and (b) $\delta=45^{\circ}$.

Regarding the tension case for $\delta=0^{\circ}$, we note that Young modulus $E(\mathbf{y})$ and Poisson ratio $v(\mathbf{x}, \mathbf{y})$ are the most degraded property (for $E(\mathbf{y})$, almost $-30 \%$ relative to its initial value at the end of the load). This stands directly in agreement with the anisotropic development of microcracking shown on the roses of the density distribution (Figure 9a). In this situation, decohesion surfaces are mainly oriented in the direction orthogonal to the loading direction $\mathbf{y}$ and preserve the initial orthotropy of the material. For tension at $\delta=45^{\circ}$, the density extent is less important and the maximum increase of density occurs at around $-15^{\circ}$ from axis $\mathbf{y}$ (Figure 9b). Yet, Young modulus $E(\mathbf{y})$ and shear modulus $G(\mathbf{x}, \mathbf{y})$ are degraded by almost the same way, while moduli $E(\mathbf{x})$ and $v(\mathbf{x}, \mathbf{y})$ are less affected than for $\delta=0^{\circ}$. These results demonstrate the specificity of anisotropy compared to isotropic case 

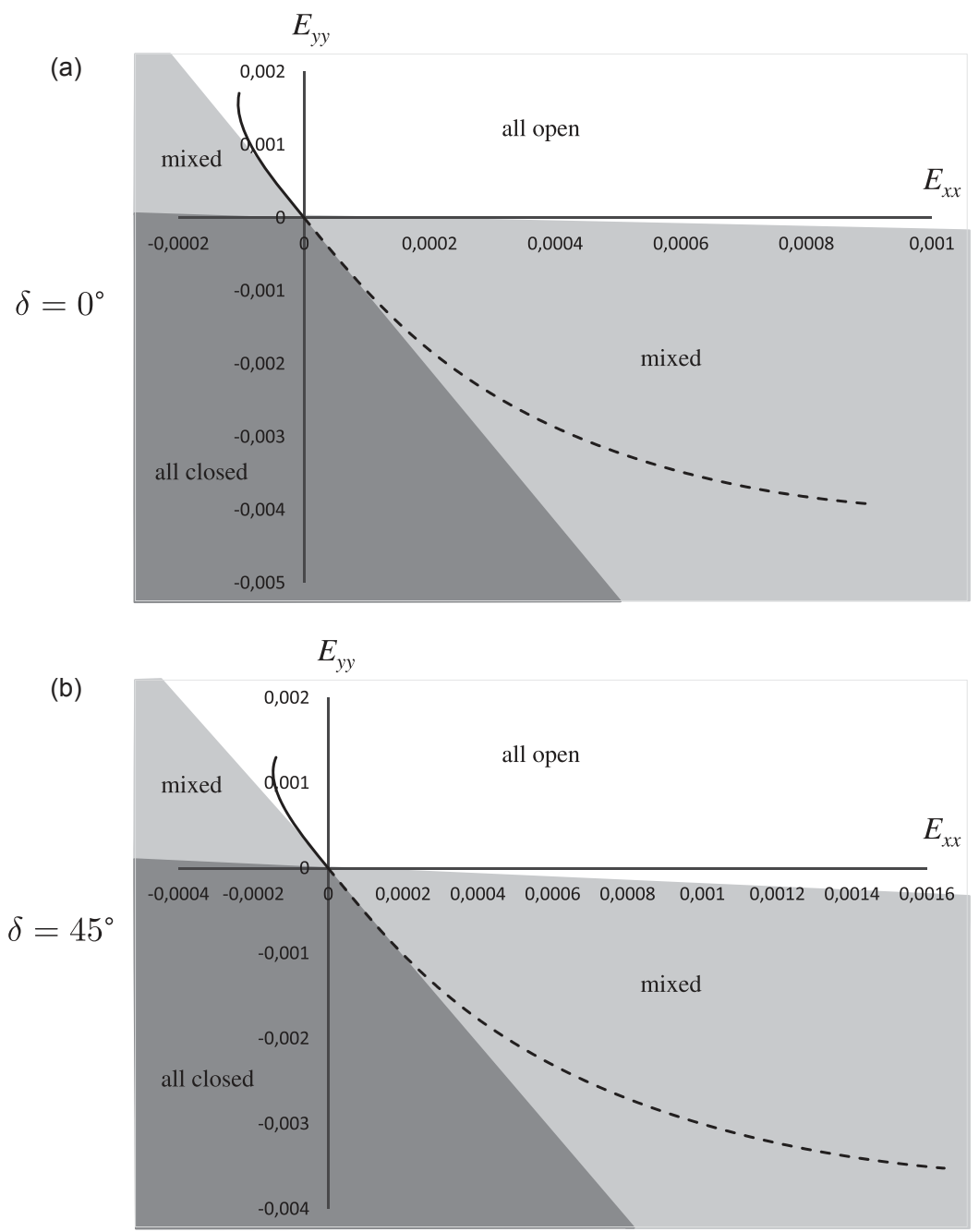

Figure II. Opening-closure domains of microcracks for a SiC-SiC composite in the strain space $\left(E_{x x}, E_{y y}\right)$ for two loading directions; loading paths for tension (full line) and compression (dashed line) tests are also represented. (a) $\delta=0^{\circ}$ and (b) $\delta=45^{\circ}$.

(see Welemane and Cormery, 2002) and illustrate the complex interactions between initial anisotropy and microcracks contributions.

For compression cases, we note a major growth of microcracks at around $\pm 42^{\circ}$ to $\mathbf{y}$ for $\delta=0^{\circ}$ (Figure 10a) and at around $-57^{\circ}$ to $\mathbf{y}$ for $\delta=45^{\circ}$ (Figure 10b). Again, resulting elastic behaviour is quite different from isotropic case, as shown by the evolutions of Young moduli $E(\mathbf{x})$ and $E(\mathbf{y})$. Also, damage influence for compression loads is mainly visible on Poisson ratio $v(\mathbf{x}, \mathbf{y})$ that increases of almost $+100 \%$ for $\delta=45^{\circ}$. Note finally that, for both tension and compression off-axis loads, the density distribution induces non-zero values of components $\mathbb{C}_{x x x y}$ and $\mathbb{C}_{x y y y}$ of the stiffness tensor, which confirms the loss of the initial orthotropic symmetry of the material. 

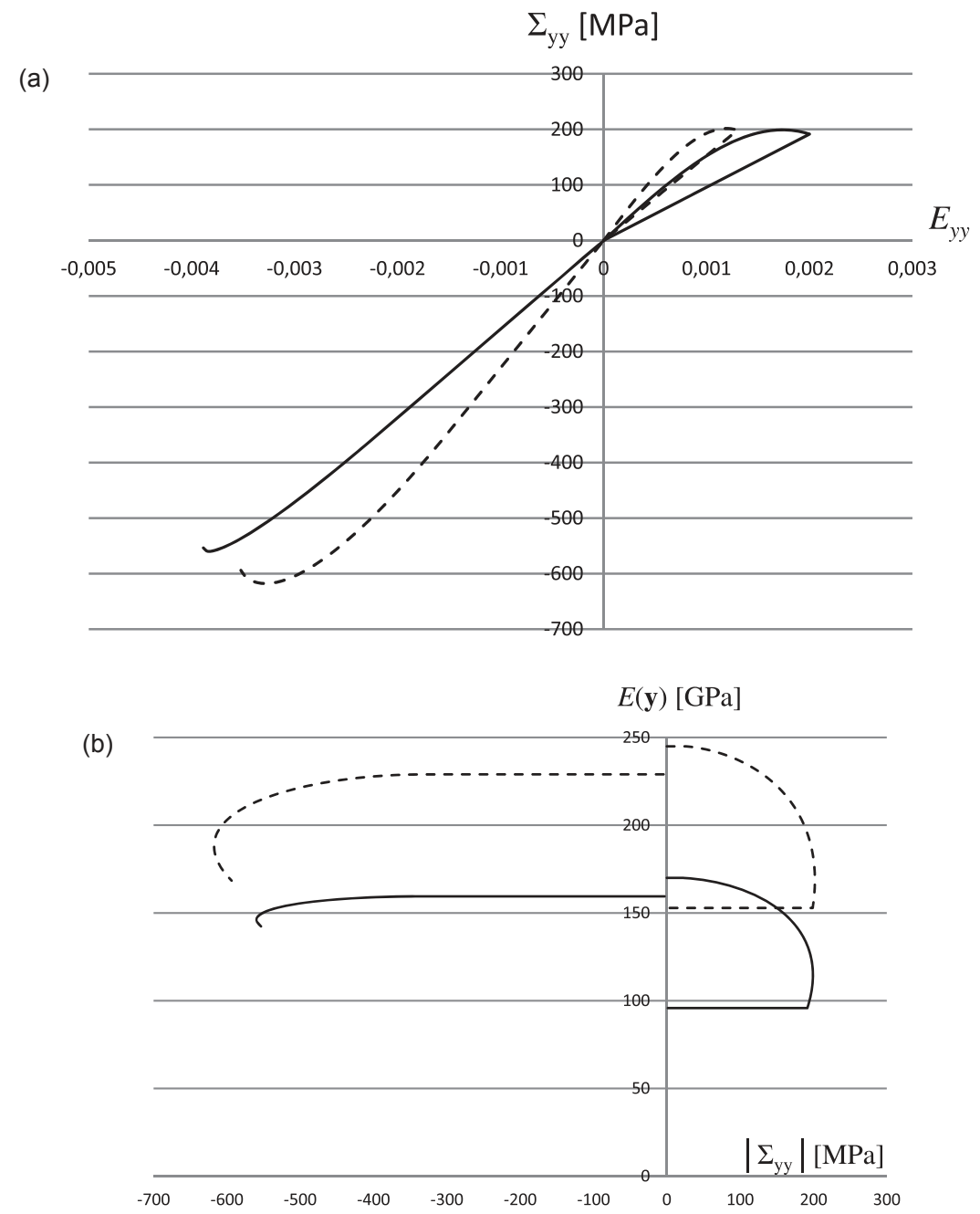

Figure 12. Uniaxial tension load followed by compression for axis (full line: $\delta=0^{\circ}$ ) and off-axis cases (dashed line: $\delta=45^{\circ}$ ): (a) axial stress-strain responses, (b) evolution of the effective Young modulus $E(\mathbf{y})$ according to the axial load $\Sigma=\Sigma_{y y} \mathbf{y} \otimes \mathbf{y}$.

It is also interesting to compare the tensile and compressive responses for a given loading orientation $\delta$. From a general point of view, the model is able to represent the dissymmetric response between tension and compression (Figure 6) and the different impact of these loads on elastic properties (the best illustration might be the Poisson ratio $v(\mathbf{x}, \mathbf{y})$ that decreases in tension and increases in compression, Figure 8). These features result solely from the account of opening-closure effects, from one single set of damages variables $\mathbf{d}$ and without any tensorial decomposition. In both loading orientations considered $\left(\delta=0^{\circ}\right.$ and $\left.\delta=45^{\circ}\right)$, all systems are open during tension (Figure 11). Regarding the compression case, microcracks initiated by the load are first all closed 
and then come progressively to a mixed situation (some get open and some remain closed). Precisely, microcracks that get open during compression are more or less parallel to the load:

- for $\delta=0^{\circ}$, microcracks with normal $\mathbf{n}$ such that $(\mathbf{x}, \mathbf{n}) \in\left[-12^{\circ}, 12^{\circ}\right]$ are open at the end of the load; due to the density distribution, the opening-closure distribution here remains then orthotropic;

- on the contrary for $\delta=45^{\circ}$, microcracks with normal $\mathbf{n}$ such that $(\mathbf{x}, \mathbf{n}) \in\left[-27^{\circ}, 6^{\circ}\right]$ are open at the end of the load; the deviation results from the complex influence of the initial anisotropy in the opening-closure criterion (8).

In addition to the density distribution, this different opening-closure state between these two configurations also explains the differences in the elastic properties evolution in compression shown in Figures 7 and 8.

To highlight again the impact of unilateral effects in such anisotropic context, simulation of an uniaxial tension load followed by compression has been performed; axis and off-axis configurations have been considered. In both cases, one can clearly see on the axial stress-strain response $\Sigma_{y y}-E_{y y}$, the recovery phenomenon at the closure of microcracks when compression load begins (Figure 12a). The evolution of the effective Young modulus $E(\mathbf{y})$ illustrates even better the different stages of this test (Figure 12b):

- from some threshold, the progressive degradation of $E(\mathbf{y})$ due to tension loading,

- during unloading, the constant value of $E(\mathbf{y})$ that keeps the minimum value induced at the end of tension load,

- the discontinuity when load gets into the compression part and the elastic property recovery associated to the closure of some microcracks; relative to the initial value of $E(\mathbf{y})$, the damage deactivation is partial, especially because some microcracks remain open (mixed state of openingclosure),

- then, from a given stage, the progressive degradation of $E(\mathbf{y})$ again due to compressive load.

\section{Concluding remarks}

A fully constitutive damage model for 2D initially orthotropic materials has been formulated in the framework of CDM. Based on a mathematical and rigorous thermodynamic framework, the formulation derives also from the micromechanical analysis of anisotropic microcracked media. The use of such homogenization procedure has notably clarified some difficult questions such as the influence of arbitrary orientation and closure effects of microcracks on the material response and damage evolution. The damage model leads to very encouraging results for the formulation of the composite materials behaviour. It accounts in a simple way for some essential characteristics of these materials, particularly the non-linearity of the response, the interaction between the initial and induced anisotropy and unilateral effects. By this way, one can represent the dependence of composites behaviour on the loading, both on its orientation (on/off axes loads) and on its nature (tension/compression).

If the first results presented here assess the modelling approach, it is nevertheless appropriate in the future to deepen this validation work against experimental results. To this end, some issues 
remain to be addressed such as the weak non-linearity or the fact that the yield stress is slightly affected by the loading orientation. Further work need then to be done to complement this basic formulation. According to the composite materials, different alternatives could be studied. As an example, previous aspects could be clearly improved by the coupling with plasticity (Zhu et al., 2008), interactions between defects (in relation with recent works of Monchiet et al., 2012) or sliding of microcracks with friction (Pensée, 2002; Zhu et al., 2011). Regarding the latter option, one of the main advantages of the model is to have an access to the status of each microcracks system; therefore, it provides a very appropriate framework for the consideration of this supplementary dissipative mechanism on the closed microcracks lips.

\section{Funding}

This research received no specific grant from any funding agency in the public, commercial, or not-for-profit sectors.

\section{References}

Allen D, Harris CE and Groves SE (1987) A thermomechanical constitutive theory for elastic composites with distributed damage - I. Theoretical development/II. Application to matrix cracking in laminated composites. International Journal of Solids and Structures 23: 1301-1338.

Allix O, Cluzel C, Gasser A, et al. (1993) Modélisation des composites céramique-céramique à différentes échelles. Revue des Composites et des Matériaux Avancés 3: 277-297.

Andrieux S, Bamberger Y and Marigo J (1986) Un modéle de matériau microfissuré pour les bétons et les roches. Journal de Mécanique théorique et appliquée 5: 471-513.

Aubard X (1995) Modelling of the mechanical behaviour of 2-D SiC-SiC composite at a mesoscale. Composites Science and Technology 54: 371-378.

Bargellini R, Halm D and Dragon A (2007) Discrete approach for modelling quasi-brittle damage: conditions on the set of directions. Comptes Rendus de Mécanique 335: 781-786.

Baste S and Aristégui C (1998) Induced anisotropy and crack systems orientations of a ceramic matrix composite under off-principal axis loading. Mechanics of Materials 29: 19-41.

Bazant Z and Oh B (1986) Efficient numerical integration on the surface of a sphere. Journal of Applied Mathematics and Mechanics/Zeitschrift für Angewandte Mathematik und Mechanik 1: 37-49.

Budiansky B and O'Connel J (1976) Elastic moduli of a cracked solid. International Journal of Solids and Structures 12: 81-97.

Carol I, Prat P and Bazant Z (1992) New explicit microplane model for concrete: Theoretical aspects and numerical implementation. International Journal of Solids and Structures 29: 1173-1191.

Carol I and Willam K (1996) Spurious energy dissipation/generation in stiffness recovery models for elastic degradation and damage. International Journal of Solids and Structures 33: 2939-2957.

Cazacu O, Soare S and Kondo D (2007) On modeling the interaction between initial and damage-induced anisotropy in transversely isotropic solids. Mathematics and Mechanics of Solids 12: 305-318.

Chaboche J (1992) On the difficulties associated with the active/passive unilateral condition. International Journal of Damage Mechanics 1: 148-171.

Chaboche JL (1999) Continuum damage mechanics: Initial and induce anisotropy in composite materials. In: Darve F and Loret B (eds) Mechanics of Heterogeneous Materials (Conference to the Memory of Prof JP Boehler). Grenoble, France: Université Joseph Fourier.

Chaboche JL, Lesne PM and Maire JF (1995) Continuum damage mechanics, anisotropy and damage deactivation for brittle materials like concrete and ceramic composites. International Journal of Damage Mechanics 4: 5-22.

Chaboche JL and Maire JF (2002) A new micromechanics based CDM model and its application to CMC's. Aerospace Science and Technology 6: 131-145. 
Christensen R (1979) Mechanics of Composite Materials. New York: Wiley \& Sons.

Cormery F and Welemane H (2002) A critical review of some damage models with unilateral effect. Mechanics Research Communications 29: 391-395.

Cormery F and Welemane H (2010) A stress-based macroscopic approach for microcracks unilateral effect. Computational Materials Science 47: 727-738.

Curnier A, He Q and Zysset P (1995) Conewise linear elastic materials. Journal of Elasticity 37: 1-38.

Desmorat R (2000) Dissymétrie de comportement élastique anisotrope couplé ou non à l'endommagement. Comptes Rendus de l'Académie des Sciences de Paris 328: 445-450.

Dragon A and Halm D (2004) Damage Mechanics - Some Modelling Challenges. Warsaw, Poland: Inst Fund Tech Research, Polish Academy of Sciences.

Feltman R and Santare M (1999) Anisotropic effective moduli of cracked short-fiber reinforced composites. Journal of Applied Mechanics 66: 709-713.

Germain P, Nguyen QS and Suquet P (1983) Continuum thermodynamics. Journal of Applied Mechanics 50: $1010-1020$.

Goidescu C (2011) Caractérisation et modélisation de l'endommagement par microfissuration des composites stratifiés-Apports des mesures de champs et de l'homogénéisation. PhD Thesis, Université de Toulouse Institut National Polytechnique de Toulouse.

Goidescu C, Welemane H, Garnier C, et al. (2013a) Damage investigation in CFRP composites using full-field measurement techniques: Combination of digital image stereo-correlation, infrared thermography and X-ray tomography. Composites Part B: Engineering 48: 95-105.

Goidescu C, Welemane H, Kondo D, et al. (2013b) Microcracks closure effects in initially orthotropic materials. European Journal of Mechanics - A/Solids 37: 172-184.

Gurson A (1977) Continuum theory of ductile rupture by void nucleation and growth - Part I: Yield criteria and flow rules for porous ductile media. Journal of Engineering Materials and Technology 99: 2-15.

Halm D, Dragon A and Charles Y (2002) A modular damage model for quasi-brittle solids - Interaction between initial and induced anisotropy. Archive of Applied Mechanics 72: 498-510.

Hashin Z (1983) Analysis of composite materials - Survey. Journal of Applied Mechanics 50: 481-505.

Hayes M (1972) Connexions between the moduli for anisotropic elastic materials. Journal of Elasticity. Vol 2.

Hill R (1965) A self consistent mechanics of composite materials. Journal of the Mechanics and Physics of Solids 13: 213-222.

Homand F, Hoxha D, Belem T, et al. (2000) Geometric analysis of damaged microcracking in granites. Mechanics of Materials 32: 361-376.

Horii H and Nemat-Nasser S (1983) Overall moduli of solids with microcracks: Load induced anisotropy. Journal of the Mechanics and Physics of Solids 31: 155-171.

Ju J (1990) Isotropic and anisotropic damage variables in continuum damage mechanics. Journal of Engineering Mechanics 116: 2764-2770.

Krajcinovic D (1987) Micromechanical basis of phenomenological models. Continuum Damage Mechanics Theory and applications. Wien: Springer-Verlag, pp. 195-206.

Krajcinovic D (1996) Damage Mechanics. The Netherlands: Elsevier Science.

Krajcinovic D (2000) Damage mechanics: Accomplishments, trends and needs. International Journal of Solids and Structures 37: 267-277.

Ladevéze P (1993) On an anisotropic damage theory. In: Boehler JP (ed.) Failure Criteria of Structured Media. Rotterdam, The Netherlands: Balkema, pp. 355-363.

Ladevéze P, Gasser A and Allix O (1994) Damage mechanisms modeling for ceramic composites. Journal of Engineering Materials and Technology 116: 331-336.

Lekhnitskii S (1963) Theory of Elasticity of Anisotropic Elastic Body. San Francisco: Holden-Day.

Levasseur S, Welemane H and Kondo D (2013) Microcracks-induced damage modelling for transversely isotropic rock. In: International Symposium on Computational Geomechanics, Krakow, Poland, 21-23 August. 
Maire JF and Chaboche JL (1997) A new formulation of continuum damage mechanics (CDM) for composite materials. Aerospace Science and Technology 4: 247-257.

Maire JF and Lesne PM (1998) An explicit damage model for the design of composites structures. Composites Science and Technology 58: 773-778.

Marigo JJ (1981) Formulation d'une loi d'endommagement d'un matériau élastique. Comptes Rendus de l'Académie des Sciences de Paris 19: 33-36.

Marigo JJ (1985) Modelling of brittle and fatigue damage for elastic material by growth of microvoids. Engineering Fracture Mechanics 21: 861-874.

Mauge C and Kachanov M (1994) Effective elastic properties of anisotropic materials with arbitrarily oriented cracks. Journal of the Mechanics and Physics of Solids 42: 1-24.

Monchiet V, Gruescu C, Cazacu, et al. (2012) A micromechanical approach of crack-induced damage in orthotropic media: Application to a brittle matrix composite. Engineering Fracture Mechanics 83: 40-53.

Morvan JM and Baste S (1998) Effect of the opening/closure of microcracks on the nonlinear behavior of a 2D C-SiC composite under cyclic loading. International Journal of Damage Mechanics 7: 381-402.

Murakami S (2012) Continuum Damage Mechanics. Tokyo: Springer.

Pensée V (2002) Contribution de la micromécanique à la modélisation tridimensionnelle de l'endommagement par mésofissuration. PhD Thesis, Université de Lille I, France.

Pensée V, Kondo D and Dormieux L (2002) Three-dimensional micromechanical approach of brittle anisotropic damage and related issues. Journal of Engineering Mechanics 128: 889-897.

Reinhardt HW (1984) Fracture mechanics of an elastic softening material like concrete. Heron 1: 42.

Talreja R (1985) A continuum mechanics characterization of damage in composite materials. Proceedings of the Royal Society of London A 399: 195-209.

Talreja R (1991) Continuum modelling of damage in ceramic matrix composites. Mechanics of Materials 12: 165-180.

Telega J (1990) Homogenization of fissured elastic solids in the presence of unilateral conditions and friction. Computational Mechanics 6: 109-127.

Thionnet A and Martin C (2006) A new constructive method using the theory of invariants to obtain material behavior laws. International Journal of Solids and Structures 43: 325-345.

Thionnet A and Renard J (1999) Modelling unilateral damage effect in strongly anisotropic materials by the introduction of the loading mode in damage mechanics. International Journal of Solids and Structures 36: 4269-4287.

Tsukrov I and Kachanov M (2000) Effective moduli of an anisotropic material with elliptical holes of arbitrary orientational distribution. International Journal of Solids and Structures 37: 5919-5941.

Wang X, Gazonas GA and Santare MH (2009) On the effective electroelastic properties of micro- cracked generally anisotropic solids. International Journal of Fracture 158: 27-40.

Welemane H and Cormery F (2002) Some remarks on the damage unilateral effect modelling for microcracked materials. International Journal of Damage Mechanics 11: 65-86.

Welemane H and Cormery F (2003) An alternative 3D model for damage induced anisotropy and unilateral effect in microcracked materials. Journal de Physique IV 105: 329-336.

Welemane H and Goidescu C (2010) Isotropic brittle damage and unilateral effect. Comptes Rendus de Mécanique 338: 271-276.

Zhu Q (2006) Applications des approches d'homogénéisation à la modélisation tridimensionnelle de l'endommagement des matériaux quasi fragiles: Formulations, validations et implémentations numériques. PhD Thesis, Université de Lille I, France.

Zhu Q, Shao JF and Kondo D (2008) A discrete thermodynamic approach for modelling anisotropic coupled plasticity-damage behavior in geomaterials. Comptes Rendus de Mécanique 336: 376-383.

Zhu Q, Shao JF and Kondo D (2011) A micromechanics-based thermodynamic formulation of isotropic damage with unilateral and friction effects. European Journal of Mechanics - A/Solids 30: 316-325. 


\section{Appendix I. Expression of coefficients}

Coefficients $\left\{c_{p}\left(\mathbb{C}^{0}, \mathbf{n}, \mathbf{A}\right)\right\}_{p=1,10}$ entering the free energy (6) take the following expressions according to the microcracks status:

- if cracks are open $(g(\mathbf{E}, \mathbf{n}, \mathbf{A})>0),\left\{c_{p}\left(\mathbb{C}^{0}, \mathbf{n}, \mathbf{A}\right)\right\}_{p=1,10}=\left\{c_{p}^{\text {open }}\left(\mathbb{C}^{0}, \mathbf{n}, \mathbf{A}\right)\right\}_{p=1,10}$

$$
\begin{aligned}
c_{1}^{\text {open }}= & -\left(2 a_{1}+a_{4}\right) a_{4}\left(k_{1}-k_{2}\right)(\mathbf{n} \cdot \mathbf{A} \cdot \mathbf{n})-a_{1}^{2}\left[k_{1}+k_{2}-2 k_{2}(\mathbf{n} \cdot \mathbf{A} \cdot \mathbf{n})\right] \\
c_{2}^{\text {open }}= & -a_{3}\left(a_{3}+2 a_{4}\right)\left(k_{1}-k_{2}\right)(\mathbf{n} \cdot \mathbf{A} \cdot \mathbf{n})-a_{4}^{2}\left[k_{1}+k_{2}-2 k_{2}(\mathbf{n} \cdot \mathbf{A} \cdot \mathbf{n})\right] \\
c_{3}^{\text {open }}= & -2\left(a_{1} a_{3}+a_{3} a_{4}+a_{4}^{2}\right)\left(k_{1}-k_{2}\right)(\mathbf{n} \cdot \mathbf{A} \cdot \mathbf{n}) \\
& -2 a_{1} a_{4}\left[k_{1}+k_{2}-2 k_{2}(\mathbf{n} \cdot \mathbf{A} \cdot \mathbf{n})\right] \\
c_{4}^{\text {open }}= & -2 a_{2}^{2} k_{2} \\
c_{5}^{\text {open }}= & -2 a_{1} a_{2}\left(k_{1}+k_{2}\right) \\
c_{6}^{\text {open }}= & -a_{2}^{2}\left[k_{1}-k_{2}+2 k_{2}(\mathbf{n} \cdot \mathbf{A} \cdot \mathbf{n})\right] \\
c_{7}^{\text {open }}= & -2 a_{2} a_{4}\left(k_{1}-k_{2}\right)+4 a_{1} a_{2} k_{2} \\
c_{8}^{\text {open }}= & -2 a_{2} a_{4}\left(k_{1}+k_{2}\right) \\
c_{9}^{\text {open }}= & -2 a_{2} a_{3}\left(k_{1}-k_{2}\right)+4 a_{2} a_{4} k_{2} \\
c_{10}^{\text {open }}= & 4 a_{2}^{2} k_{2}
\end{aligned}
$$

- if cracks are closed $(g(\mathbf{E}, \mathbf{n}, \mathbf{A}) \leq 0),\left\{c_{p}\left(\mathbb{C}^{0}, \mathbf{n}, \mathbf{A}\right)\right\}_{p=1,10}=\left\{c_{p}^{c l o s}\left(\mathbb{C}^{0}, \mathbf{n}, \mathbf{A}\right)\right\}_{p=1,10}$

$$
\begin{aligned}
c_{1}^{c l o s}= & -\frac{(\mathbf{n} \cdot \mathbf{A} \cdot \mathbf{n})[1-(\mathbf{n} \cdot \mathbf{A} \cdot \mathbf{n})]}{k_{1}^{2}-k_{2}^{2}}\left[a_{4}\left(k_{1}-k_{2}\right)-2 a_{1} k_{2}\right] \\
& \times\left[\begin{array}{l}
2 a_{1} k_{2}\left[k_{1}+k_{2}-2 k_{2}(\mathbf{n} \cdot \mathbf{A} \cdot \mathbf{n})\right] \\
+a_{4}\left(k_{1}-k_{2}\right)\left[k_{1}+k_{2}+2 k_{2}(\mathbf{n} \cdot \mathbf{A} \cdot \mathbf{n})\right]
\end{array}\right] \\
c_{2}^{c l o s}= & -\frac{(\mathbf{n} \cdot \mathbf{A} \cdot \mathbf{n})[1-(\mathbf{n} \cdot \mathbf{A} \cdot \mathbf{n})]}{k_{1}^{2}-k_{2}^{2}}\left[a_{3}\left(k_{1}-k_{2}\right)-2 a_{4} k_{2}\right] \\
& \times\left[\begin{array}{l}
2 a_{4} k_{2}\left[k_{1}+k_{2}-2 k_{2}(\mathbf{n} \cdot \mathbf{A} \cdot \mathbf{n})\right] \\
+a_{3}\left(k_{1}-k_{2}\right)\left[k_{1}+k_{2}+2 k_{2}(\mathbf{n} \cdot \mathbf{A} \cdot \mathbf{n})\right]
\end{array}\right] \\
c_{3}^{c l o s}= & \frac{2(\mathbf{n} \cdot \mathbf{A} \cdot \mathbf{n})[1-(\mathbf{n} \cdot \mathbf{A} \cdot \mathbf{n})]}{k_{1}^{2}-k_{2}^{2}} \\
& \times\left[\begin{array}{l}
4 a_{4} k_{2}^{2}\left[\begin{array}{l}
a_{4}\left(k_{1}-k_{2}\right)(\mathbf{n} \cdot \mathbf{A} \cdot \mathbf{n}) \\
+a_{1}\left[k_{1}+k_{2}-2 k_{2}(\mathbf{n} \cdot \mathbf{A} \cdot \mathbf{n})\right]
\end{array}\right] \\
+a_{3}\left(k_{1}-k_{2}\right)\left[\begin{array}{l}
4 a_{1} k_{2}^{2}(\mathbf{n} \cdot \mathbf{A} \cdot \mathbf{n}) \\
-a_{4}\left(k_{1}-k_{2}\right)\left[k_{1}+k_{2}+2 k_{2}(\mathbf{n} \cdot \mathbf{A} \cdot \mathbf{n})\right]
\end{array}\right]
\end{array}\right.
\end{aligned}
$$




$$
\begin{aligned}
& c_{4}^{\text {clos }}=\frac{a_{2}^{2}}{k_{1}^{2}-k_{2}^{2}}\left[\begin{array}{l}
k_{1}^{3}-k_{1} k_{2}\left[k_{1}+k_{2}-2 k_{1}(\mathbf{n} \cdot \mathbf{A} \cdot \mathbf{n})\right] \\
+k_{2}^{3}\left[1+6(\mathbf{n} \cdot \mathbf{A} \cdot \mathbf{n})-8(\mathbf{n} \cdot \mathbf{A} \cdot \mathbf{n})^{2}\right]
\end{array}\right] \\
& c_{5}^{c l o s}=\frac{2 a_{2}(\mathbf{n} \cdot \mathbf{A} \cdot \mathbf{n})}{k_{1}-k_{2}}\left[\begin{array}{l}
4 a_{1} k_{2}^{2}[1-(\mathbf{n} \cdot \mathbf{A} \cdot \mathbf{n})] \\
+a_{4}\left(k_{1}-k_{2}\right)\left[k_{1}-k_{2}+2 k_{2}(\mathbf{n} \cdot \mathbf{A} \cdot \mathbf{n})\right]
\end{array}\right] \\
& c_{6}^{\text {clos }}=-\frac{a_{2}^{2}}{k_{1}^{2}-k_{2}^{2}}\left[k_{1}-k_{2}+2 k_{2}(\mathbf{n} \cdot \mathbf{A} \cdot \mathbf{n})\right] \\
& \times\left[k_{1}^{2}-k_{2}^{2}\left[1+4(\mathbf{n} \cdot \mathbf{A} \cdot \mathbf{n})-4(\mathbf{n} \cdot \mathbf{A} \cdot \mathbf{n})^{2}\right]\right] \\
& c_{7}^{\text {clos }}=-\frac{2 a_{2}}{k_{1}^{2}-k_{2}^{2}}\left[\begin{array}{l}
8 a_{1} k_{2}^{3}(\mathbf{n} \cdot \mathbf{A} \cdot \mathbf{n})[1-(\mathbf{n} \cdot \mathbf{A} \cdot \mathbf{n})] \\
+a_{4}\left(k_{1}-k_{2}\right)\left[\begin{array}{l}
k_{1}^{2}+2 k_{1} k_{2}(\mathbf{n} \cdot \mathbf{A} \cdot \mathbf{n}) \\
-k_{2}^{2}\left[1+2(\mathbf{n} \cdot \mathbf{A} \cdot \mathbf{n})-4(\mathbf{n} \cdot \mathbf{A} \cdot \mathbf{n})^{2}\right]
\end{array}\right]
\end{array}\right] \\
& c_{8}^{\text {clos }}=\frac{2 a_{2}(\mathbf{n} \cdot \mathbf{A} \cdot \mathbf{n})}{k_{1}-k_{2}}\left[\begin{array}{l}
4 a_{4} k_{2}^{2}[1-(\mathbf{n} \cdot \mathbf{A} \cdot \mathbf{n})] \\
+a_{3}\left(k_{1}-k_{2}\right)\left[k_{1}-k_{2}+2 k_{2}(\mathbf{n} \cdot \mathbf{A} \cdot \mathbf{n})\right]
\end{array}\right] \\
& c_{9}^{\text {clos }}=-\frac{2 a_{2}}{k_{1}^{2}-k_{2}^{2}}\left[\begin{array}{l}
8 a_{4} k_{2}^{3}(\mathbf{n} \cdot \mathbf{A} \cdot \mathbf{n})[1-(\mathbf{n} \cdot \mathbf{A} \cdot \mathbf{n})] \\
+a_{3}\left(k_{1}-k_{2}\right)\left[\begin{array}{l}
k_{1}^{2}+2 k_{1} k_{2}(\mathbf{n} \cdot \mathbf{A} \cdot \mathbf{n}) \\
-k_{2}^{2}\left[1+2(\mathbf{n} \cdot \mathbf{A} \cdot \mathbf{n})-4(\mathbf{n} \cdot \mathbf{A} \cdot \mathbf{n})^{2}\right]
\end{array}\right]
\end{array}\right] \\
& c_{10}^{\text {clos }}=-\frac{16 k_{2}^{3} a_{2}^{2}}{k_{1}^{2}-k_{2}^{2}}(\mathbf{n} \cdot \mathbf{A} \cdot \mathbf{n})[1-(\mathbf{n} \cdot \mathbf{A} \cdot \mathbf{n})]
\end{aligned}
$$

with

$$
\begin{aligned}
& k_{1}=\left(\sqrt{a_{1}+a_{2}+a_{3}+2 a_{4}}+\sqrt{a_{1}+a_{2}}\right) ; K \\
& k_{2}=\left(\sqrt{a_{1}+a_{2}+a_{3}+2 a_{4}}-\sqrt{a_{1}+a_{2}}\right) ; K \\
& K=\frac{\pi}{2 \sqrt{2}} \frac{\sqrt{\frac{1}{a_{2}}+\frac{1}{a_{1}+a_{4}+\sqrt{\left(a_{1}+a_{2}\right)\left(a_{1}+a_{2}+a_{3}+2 a_{4}\right)}}}}{\sqrt{\left(a_{1}+a_{2}\right)\left(a_{1}+a_{2}+a_{3}+2 a_{4}\right)-\left(a_{1}+a_{4}\right)^{2}}}
\end{aligned}
$$

Coefficients $\left\{\eta_{p}\left(\mathbb{C}^{0}, \mathbf{n}, \mathbf{A}\right)\right\}_{p=1,4}$ entering the opening-closure characteristic function (8) are given by

$$
\begin{aligned}
& \eta_{1}=a_{2}\left(k_{1}+k_{2}\right) \\
& \eta_{2}=a_{1}\left[k_{1}+k_{2}-2 k_{2}(\mathbf{n} \cdot \mathbf{A} \cdot \mathbf{n})\right]+a_{4}\left(k_{1}-k_{2}\right)(\mathbf{n} \cdot \mathbf{A} \cdot \mathbf{n}) \\
& \eta_{3}=a_{4}\left[k_{1}+k_{2}-2 k_{2}(\mathbf{n} \cdot \mathbf{A} \cdot \mathbf{n})\right]+a_{3}\left(k_{1}-k_{2}\right)(\mathbf{n} \cdot \mathbf{A} \cdot \mathbf{n}) \\
& \eta_{4}=-2 a_{2} k_{2}
\end{aligned}
$$

